\title{
Convection-permitting Modeling Strategies for Simulating Extreme Rainfall Events Over Southeastern South America
}

\section{Martín Feijoó ( $\square$ martin.feijoo@cima.fcen.uba.ar)}

Centro de Investigaciones del Mar y la Atmosfera https://orcid.org/0000-0001-5343-3609

\section{Silvina Solman}

CIMA: Centro de Investigaciones del Mar y la Atmosfera

\section{Research Article}

Keywords: extreme rainfall , convection-permitting modeling, Southeastern South America, domain configuration

Posted Date: July 24th, 2021

DOI: https://doi.org/10.21203/rs.3.rs-675470/v1

License: (c) (1) This work is licensed under a Creative Commons Attribution 4.0 International License.

Read Full License

Version of Record: A version of this preprint was published at Climate Dynamics on March 12th, 2022. See the published version at https://doi.org/10.1007/s00382-022-06226-z. 


\title{
Convection-permitting modeling strategies for
}

\section{South America}

\author{
M. Feijoó · S. Solman
}

Received: date / Accepted: date

\begin{abstract}
A set of six convection-permitting (CP) domain configurations were implemented to perform 72-hour long simulations of three extreme precipitation events over Southeastern South America (SESA). The goal of the study is to determine the most adequate configuration for reproducing not only the rainfall evolution and intensity, but also the synoptic triggering mechanisms that led to these extreme events, taking into account the trade-off between model performance and computational cost. This study assesses the impact of 1) the horizontal resolution in the CP domain, 2) the horizontal resolution of the driver domain, 3) the size of both CP and driver domains and 4) the nesting strategy (one-step versus two-step nesting). Each simulation was performed with the Weather Research and Forecasting model driven by the ERA-Interim reanalysis. For each event and
\end{abstract}

\section{Feijoó}

Universidad de Buenos Aires, Facultad de Ciencias Exactas y Naturales. Buenos Aires, Argentina.

Centro de Investigaciones del Mar y la Atmósfera (CIMA). CONICET - Universidad de Buenos Aires. Buenos Aires, Argentina.

Instituto Franco-Argentino para el Estudio del Clima y sus Impactos (IRL 3351 IFAECI). CNRS - IRD - CONICET - UBA. Buenos Aires, Argentina.

E-mail: martin.feijoo@cima.fcen.uba.ar

S. Solman

Centro de Investigaciones del Mar y la Atmósfera (CIMA). CONICET - Universidad de Buenos Aires. Buenos Aires, Argentina.

Instituto Franco-Argentino para el Estudio del Clima y sus Impactos (IRL 3351 IFAECI). CNRS - IRD - CONICET - UBA. Buenos Aires, Argentina.

Universidad de Buenos Aires, Facultad de Ciencias Exactas y Naturales, Departamento de Ciencias de la Atmósfera y los Océanos. Buenos Aires, Argentina. 
31 Declarations

32 Funding

33 This study has been supported UBACYT2018 Grant 20020170100117BA and FONCYT Grant PICT2018-02496.

35

36 Not applicable

$37 \quad$ Availability of data and material

38 Not applicable 
Code availability

Not applicable

All authors included in the authors list have contributed on different aspects of 42 the manuscript.

\section{Introduction}

Southeastern South America (SESA) hosts some of the most extreme convective storms of the planet (Zipser et al, 2006), accounting for more than $70 \%$ of the total extended summer precipitation in the region (Rasmussen et al, 2016). This certainly makes extreme precipitation events of critical relevance, not only because of the high vulnerability of the population and the socio-economic activities (Vörösmarty et al, 2013), but also given that extreme precipitation has been increasing in frequency and intensity during the last decades (Penalba and Robledo, 2010; Cerón et al, 2020; Olmo et al, 2020). Additionally, the frequency and intensity of these events are expected to continue increasing in response to the future global warming, as revealed in several studies based on either global climate models (GCMs) or regional climate models (RCMs) (Chou et al, 2014; Blazquez and Solman, 2020).

Though several studies have demonstrated the added value of RCMs in repro- $\quad{ }^{57}$ ducing regional scale phenomena and precipitation-related features over several 58 areas of the world (Torma et al 2015 for Europe; Falco et al 2019 and Solman 59 and Blazquez 2019 for South America, among others), RCMs are still deficient in 60 reproducing extreme precipitation features mostly related with the limitations of 61 the convective schemes (Prein et al, 2015). Particularly over SESA, RCMs have ${ }_{62}$ deficiencies in reproducing the intensity of extreme rainfall events and the exten- ${ }_{63}$ sion of the region where the most intense events occur (e.g. Solman et al, 2013; 
Solman, 2016; Solman and Blazquez, 2019; Olmo and Bettolli, 2021, among others). Hence, there is an urgent need for implementing new modelling strategies to improve the capability of reproducing one of the most important climatic features in the region.

Advances in computational development allowed the implementation of models operating at convection-permitting (CP) resolutions, of the order of a few kilometers (Prein et al, 2015, 2020b, and references therein). Several studies showed that $\mathrm{CP}$ models (CPMs) outperform coarser RCMs in terms of their capacity in capturing the diurnal cycle of convective summer precipitation, the intensity of extreme precipitation events and orography-triggered convection (Matsudo et al, 2015; Prein et al, 2013; Mahoney et al, 2012; Kendon et al, 2012). In early stages, these simulations were developed in the framework of the numerical weather prediction, in which simulations were performed for a few days covering the development of a specific event (e.g. Mahoney et al, 2012). More recently, CP climatic simulations covering a decade or more have been performed over different regions within Europe (e.g. Ban et al, 2020; Berthou et al, 2020; Kendon et al, 2012) and North America (e.g. Prein et al, 2020a). These studies highlight the benefits of CPMs in representing extreme precipitation features. CPMs have also been used to explore how extreme rainfall may change under future warming scenarios (e.g. Kendon et al, 2014, 2016; Fosser et al, 2016; Ban et al, 2015; Rasmussen et al, 2020) showing that these models project larger increases in extreme rainfall compared with coarser models. Due to the high computational cost of CP climatic simulations, most CP modelling exercises have been largely based on a single modelling approach. Only recently a coordinated effort based on decade-long multi-CP model simulations started to emerge mostly for domains over Europe (e.g. Coppola et al, 2020; Ban et al, 2021; Pichelli et al, 2021).

Given the computational demand for performing ensemble simulations for a decade or more with CPMs, studies based on multiple CPMs simulating shorter periods, centered on single extreme precipitation events or on a single rainy season, 
also emerged over several regions of the world, including Europe, North America, 94 Asia and Africa (e.g. Pall et al, 2017; Hibino et al, 2018; Coppola et al, 2020; Li 95 et al, 2019, 2018; Yang et al, 2017; Matsui et al, 2020). For South America, there 96 are only some preliminary studies, (e.g. Lavín Gullón et al, 2021; Bettolli et al, ${ }_{97}$ 2021; Solman et al, 2021), that highlight the benefits of CP models in capturing 98 the main features of individual extreme events and their synoptic forcings. The 99 studies by Lavín Gullón et al (2021) and Bettolli et al (2021) arose as a collabora- 100 tive effort in the context of a CORDEX Flagship pilot study (https://cordex.org/) 101 which produced a 6 month-length simulation performed with two CP RCMs, al- ${ }_{102}$ lowing for exploring model uncertainty in capturing selected extreme events, while $\quad 103$ Solman et al (2021) assessed the quality of a single model operating at CP res- ${ }_{104}$ olution in capturing the main features of a collection of extreme precipitation 105 events in a single event approach. The domain of CP simulations in these studies 106 spanned roughly $12^{\circ} \times 12^{\circ}$ degrees with approximately $350 \times 350$ grid points and 107 were performed in a two-step nesting approach, with the CPM operating at $4 \mathrm{~km} \quad 108$ resolution, nested into a 20km-resolution domain. The results arising from these 109 experiments showed that though the CP domain covered a large part of the re- ${ }_{110}$ gion where extreme events developed, several events fell too close to the lateral 111 boundaries, suggesting that a larger CPM domain may be more adequate. Further- $\quad{ }_{112}$ more, the two-step nesting approach introduced some deviations in the low-level ${ }_{113}$ circulation as a result of convective processes occurring close to the boundaries ${ }_{114}$ of the CP domain, modulating the main synoptic drivers of the events developing $\quad 115$ within the CPM domain. As discussed in Brisson et al (2015) both the nesting ${ }_{116}$ strategy and the domain size represent two key elements in the design of CPM ${ }_{117}$ simulations, with important consequences in both the quality and the computa- ${ }_{118}$ tional cost of the simulations. Though studies assessing the sensitivity of CPM ${ }_{119}$ simulations to domain size are quite a few, it is recommended that the domain 120 size should be large enough to allow for a spatial spin-up of barely $150 \mathrm{~km}$ (Brisson $\quad{ }_{121}$ et al, 2015). However, an exceedingly large domain can generate deviations from $\quad 122$ 
the lateral boundary conditions (LBC) and have undesired effects in the outflow boundary (Prein et al, 2015). Moreover, given the control of the synoptic drivers on the development of organized convection in SESA (Lavín Gullón et al, 2021; Solman et al, 2021, among others), the domain size in CPMs in the region should be large enough so that the forcing mechanisms driving to the occurrence of extreme rainfall events, often modulated by topographic features, are included in the domain.

The nesting strategy is another important source of model uncertainty and impacts on the computational cost of a CPM simulation as well. Most of the studies based on CPM simulations are performed using either three-step nesting in a telescoping mode (e.g. Fosser et al, 2014), two-step nesting (e.g. Ban et al, 2021) or one-step nesting in which the CPM is driven by the reanalysis (e.g. Berthou et al 2020 for an European domain; Yun et al 2020 for a domain centered in eastern China; Liu et al 2017 for a domain over North America, among others). As discussed in Brisson et al (2015) multiple nestings may deteriorate the quality of a CPM simulation. On the other hand, in a one-step nesting approach, the resolution jump between the model providing the initial and lateral boundary conditions and the CP model impacts on the spatial spin-up, i.e, the distance from the boundaries of the CP domain that should be discarded (Matte and LucasPicher, 2017). Therefore, a sensitivity analysis to the nesting configuration needs to be performed to find the optimum CPM configuration for the SESA region.

Finally, the horizontal resolution in the CPM simulations is another key aspect to consider. CPM simulations operate at km-scale resolutions, from $4 \mathrm{~km}$ (the upper limit for convection permitting simulations) to roughly $2 \mathrm{~km}$. However, the benefits of higher resolution in the CPM simulations are not fully explored. Considering that the choice of the spatial resolution also impacts on the computational cost of a simulation, a sensitivity analysis of the extent to which higher resolution implies better model performance needs to be tackled. 
A careful design of CPM simulations, including the domain location, domain size, the spatial resolution and the nesting strategy should be considered to identify the optimal model configuration that allows, on one hand, capturing the extreme precipitation events of a given region and the mechanisms that contribute to trigger, develop and sustain the deep moist organized convection and, on the other hand, accounting for the tradeoff with computational costs. The experimental design described below will allow answering specific questions such as: Does the resolution of the driving model matters? Is there any significant improvement when increasing the resolution of the CPM simulations? Does the nesting strategy affect the quality of the CPM simulation? Does the domain size of the CPM simulation have an impact on the ability of capturing the evolution of an extreme event?

The goal of this study is identifying the optimal modelling strategy for perform- ${ }^{163}$ ing computationally feasible CPM simulations able to represent the main features $\quad 164$ of the extreme precipitation in SESA. Given the key forcing mechanisms leading $\quad 165$ to the formation of organized convection and subsequent extreme precipitation $\quad 166$ over SESA, including the northerly wind channeled by the Andes favoring mois- ${ }_{167}$ ture and heat flux together with a midlevel trough located over the Andes and an $\quad 168$ upper level jet stream with its associated upper level divergence (Rasmussen and ${ }_{169}$ Houze, 2016, and references therein), it is important to explore the extent to which 170 including these forcing mechanisms within the CPM domain translate in a good 171 representation of extreme events. With this aim, a series of short-term simulations 172 have been performed with the WRF RCM (version 3.9.1; Skamarock et al, 2008) 173 for a variety of domain sizes, horizontal resolutions and nesting strategies for a 174 set of individual extreme precipitation events registered in SESA. The individ- 175 ual event approach (Solman et al, 2021) allows for exploring the capability of the 176 model in capturing the event but also exploring if the model is able to capture the $\quad 177$ corresponding triggering mechanisms. Identifying a CPM set up with a good per- 178 
formance and with the lowest computational cost is needed before starting longer term simulations in the region.

The manuscript is organized as follows. In section 2 the datasets used for model validation together with the description of the model used, the experiment design and the metrics defined to assess model performance are described. In section 3 the results of the capability of the model in reproducing the selected events for the variety of model configurations and nesting strategies is described. The focus of the evaluation is on the main features of the extreme rainfall event and the synoptic forcing mechanisms. Finally, in section 4 a summary of the main results and a discussion is presented.

\section{Data and methods}

2.1 Datasets for validation

For precipitation validation, three satellite precipitation estimates are used: the NOAA's Climate Prediction Center Morphing Technique bias-corrected product (Joyce et al, 2004, CMORPH), the Global Precipitation Measurement Mission Integrated Multisatellite Retrievals calibrated precipitation Level-3 Final Run (Huffman et al, 2019, IMERG) and the Multi-Source Weighted-Ensemble Precipitation V2.1 estimate dataset (MSWEP) described in Beck et al (2018). These datasets are based on integrating different types of satellite and ground station data. Some studies using CMORPH over SESA have reported wet biases in both extreme and weak precipitation (e.g. Salio et al, 2014; Matsudo et al, 2015; Demaria et al, 2011). Similar biases as those found for CMORPH were found for IMERG data by Cui et al (2019) but in assessing rainfall associated with mesoscale convective systems (MCSs) over the great plains in the USA. MSWEP merges gauge, satellite and 202 reanalysis products and has been shown it has a good performance in monthly ${ }_{203}$ and seasonal scales over several regions of the world (Beck et al, 2017). Table 1204 lists information on the spatial and temporal resolution of the selected datasets. 205 


\begin{tabular}{lll}
\hline Dataset & Temporal resolution (hs) & Spatial resolution \\
\hline CMORPH & 0.5 & $0.0727^{\circ}$ \\
IMERG & 0.5 & $0.1^{\circ}$ \\
MSWEP & 3 & $0.1^{\circ}$ \\
\hline
\end{tabular}

Table 1 Datasets used for the evaluation of the extreme precipitation events.

The ERA-Interim reanalysis at $0.75^{\circ} \times 0.75^{\circ}$ spatial resolution (Dee et al, 2011) 206 dataset was used to provide the initial and lateral boundary conditions for the 207 simulations described in Sect. 2.3. For evaluating the model performance in terms $\quad 208$ of the triggering circulation patterns for individual extreme precipitation events, $\quad 209$ both the ERA-Interim reanalysis and the ERA5 reanalysis (Hersbach et al, 2020) ${ }_{210}$ were used. ERA5 was included in the evaluation in order to compare the modelled ${ }_{211}$ circulation features against a reanalysis dataset operating at higher resolution ${ }_{212}$ (roughly $31 \mathrm{~km}$ ) and with better performance, compared with driving ERA-Interim $\quad 213$ reanalysis (Hersbach et al, 2019).

Daily rainfall data from the gridded Tropical Rainfall Measurement Mission (TRMM) 216 3B42 V7 (Huffman et al, 2011) dataset for the period 2000 to 2017 was used to ${ }_{217}$ identify the extreme rainfall events. First, the $95^{\text {th }}$ percentile of rainy days (rain- ${ }_{218}$ fall above $1 \mathrm{~mm} /$ day) was computed for every grid point within the SESA region. $\quad 219$ Extreme precipitation at a given day is defined when precipitation is above the ${ }_{220}$ $95^{\text {th }}$ percentile at a given grid point and at adjacent grid points within a region ${ }_{221}$ of $1.25^{\circ} \times 1.25^{\circ}$ size. These criteria allowed identifying extreme events with a min- ${ }_{222}$ imum spatial extension accounting for organized convection in the region. After ${ }_{223}$ applying these criteria, three extreme events were selected. A detailed description $\quad{ }^{224}$ of the events can be found in section 3.1. 


\begin{tabular}{lllllll}
\hline Member & $\mathbf{1}$ & $\mathbf{2}$ & $\mathbf{3}$ & $\mathbf{4}$ & $\mathbf{5}$ & $\mathbf{6}$ \\
\hline MP & WDM6 & WDM6 & WDM6 & WDM6 & WSM6 & WDM6 \\
Cumulus & KF & KF & KF & KF & GF & KF \\
PBL & MJY & YSU & YSU & MYNN3 & MYNN3 & MYNN3 \\
ShCu & - & - & GRIMS & - & GRIMS & GRIMS \\
LW Rad & Dudhia & Dudhia & Dudhia & Dudhia & Dudhia & Dudhia \\
SW Rad & RRTM & RRTM & RRTM & RRTM & RRTM & RRTM \\
SfcLay & ETA S & Rev. MM5 & Rev. MM5 & ETA S & ETA S & ETA S \\
Land & UNOAH & UNOAH & UNOAH & UNOAH & UNOAH & UNOAH \\
\hline
\end{tabular}

Table 2 Selection of physics schemes used for each member of the physics ensemble. Cumulus parameterization in the CP domains is turned off. Acronyms used: $M P$ : Microphysics scheme, $P B L$ : Planet boundary layer scheme, ShCu: Shallow cumulus scheme, $L W R a d / S W$ Rad: Lonwave and Shortwave radiation scheme, SfcLay: Surface Layer scheme, Land: Land Surface scheme. WDM6/WSM6: Lim and Hong (2010); KF: Kain (2004); GF: Grell and Freitas (2014); MJY: Janjic (1994); YSU: Hong et al (2006); MYNN3: Nakanishi and Niino (2009); GRIMS: Hong and Jang (2018); Dudhia: Dudhia (1989); RRTM: Mlawer et al (1997); ETA S: Janjic (2002); Rev MM5: Jimenez et al (2012); UNOAH: Tewari et al (2016).

2.3 The WRF model and experimental design

The Weather Research and Forecast model (WRF; Skamarock et al, 2008) version $\quad 227$ 3.9.1 was used in this study to perform short-term (72-hour) simulations for the ${ }_{228}$ selected extreme events. For each event, the model was initialized at 00 UTC of ${ }_{229}$

the day before the occurrence of the extreme event, being the first 6 hours of the simulations considered as spin-up time and, therefore, discarded for the analysis. Both initial and lateral boundary conditions (LBC) were provided by the $0.75^{\circ}$ horizontal resolution ERA-Interim reanalysis. All simulations were performed with 39 vertical levels. The relaxation zone at the boundaries has an extension of around $0.75^{\circ}$

For each event and for each model configuration, a physics ensemble was built to account for model uncertainty. The members of the physics ensemble differ mainly in the cumulus, microphysics, planetary boundary layer and shallow convection parameterizations. The physics ensemble comprises 6 members, as described in Table 2. The analysis of the CPM simulations described below is based on the physics ensemble mean. 


\begin{tabular}{|c|c|c|c|c|c|c|c|}
\hline & \multicolumn{3}{|c|}{ DR } & \multicolumn{3}{|c|}{$\mathrm{CP}$} & \multirow[b]{2}{*}{ Name } \\
\hline & $\Delta \mathrm{x}$ & $\begin{array}{l}\text { no. of } \\
\text { pts }\end{array}$ & $\begin{array}{l}\text { Lon range } \\
\text { Lat range }\end{array}$ & $\Delta \mathrm{x}$ & $\begin{array}{l}\text { no. of } \\
\text { pts }\end{array}$ & $\begin{array}{l}\text { Lon range } \\
\text { Lat range }\end{array}$ & \\
\hline D1 & $12 \mathrm{~km}$ & $\begin{array}{c}52192 \\
"\end{array}$ & $\begin{array}{c}76^{\circ} \mathrm{W}, 46^{\circ} \mathrm{W} \\
43^{\circ} \mathrm{S}, 19^{\circ} \mathrm{S} \\
,\end{array}$ & $\begin{array}{c}2.4 \mathrm{~km} \\
4 \mathrm{~km}\end{array}$ & $\begin{array}{l}300696 \\
103648\end{array}$ & $\begin{array}{c}66^{\circ} \mathrm{W}, 53^{\circ} \mathrm{W} \\
37^{\circ} \mathrm{S}, 25^{\circ} \mathrm{S} \\
,\end{array}$ & $\begin{array}{c}\text { CP1-2.4(12) } \\
\text { CP1-4(12) }\end{array}$ \\
\hline D2 & $\begin{array}{c}12 \mathrm{~km} \\
20 \mathrm{~km} \\
-\end{array}$ & $\begin{array}{c}154280 \\
55404 \\
-\end{array}$ & $\begin{array}{c}87^{\circ} \mathrm{W}, 37^{\circ} \mathrm{W} \\
47^{\circ} \mathrm{S}, 7^{\circ} \mathrm{S} \\
,\end{array}$ & $\begin{array}{l}4 \mathrm{~km} \\
4 \mathrm{~km} \\
4 \mathrm{~km}\end{array}$ & $\begin{array}{c}279220 \\
, \\
",\end{array}$ & $\begin{array}{c}77^{\circ} \mathrm{W}, 52^{\circ} \mathrm{W} \\
39^{\circ} \mathrm{S}, 23^{\circ} \mathrm{S} \\
" \\
"\end{array}$ & $\begin{array}{c}\text { CP2-4(12) } \\
\text { CP2-4(20) } \\
\text { CP2-4 }\end{array}$ \\
\hline D3 & - & - & - & $4 \mathrm{~km}$ & 426960 & $\begin{array}{c}77^{\circ} \mathrm{W}, 48^{\circ} \mathrm{W} \\
36^{\circ} \mathrm{S}, 15^{\circ} \mathrm{S}\end{array}$ & CP3-4 \\
\hline
\end{tabular}

Table 3 Summary of the experimental set-up including the domain name, the horizontal resolution $(\Delta \mathrm{x})$, the number of gridpoints (no. of pts), the spatial coverage and the name of the CP simulations. DR denotes the driving domain and CP denotes the convection-permitting domain.

The three selected events were simulated using a set of different domain configurations, including different nesting strategies (two-steps nesting vs one-step nesting), different domain sizes for both the two domains in the two-step nesting approach and the single domain for the one-step nesting approach, and different spatial resolutions (including the spatial resolution of the outer domain in the two-step nesting approach and the CPM domain). This experimental setup includes three domain sizes referred to as D1, D2 and D3. For each domain size, the two-step nesting includes the outer domain driven by the reanalysis, referred to as the driving domain (DR) which provides the lateral boundary conditions to a smaller domain at convection-permitting resolution $(\mathrm{CP})$, corresponding to the CP domain. Accordingly, the difference in the physics choices between DR and CP domains is that the convective scheme is switched on or off, respectively. Figure 1 shows the driving and the convection-permitting-resolution domains for the three domain sizes and Table 3 summarizes the description of the simulations. Considering all combinations displayed in Tables 1 and 3, a total of 36 simulations have been performed for each individual event, with 6 ensemble members for 6 different model set-ups.

Simulations performed at D1 include the DR1 domain with a horizontal resolution of $12 \mathrm{~km}$ (roughly 50K grid points) and the CP1 domain at two horizontal resolutions: $2.4 \mathrm{~km}$ (roughly $300 \mathrm{~K}$ grid points) and 4km (roughly $100 \mathrm{~K}$ grid points), 


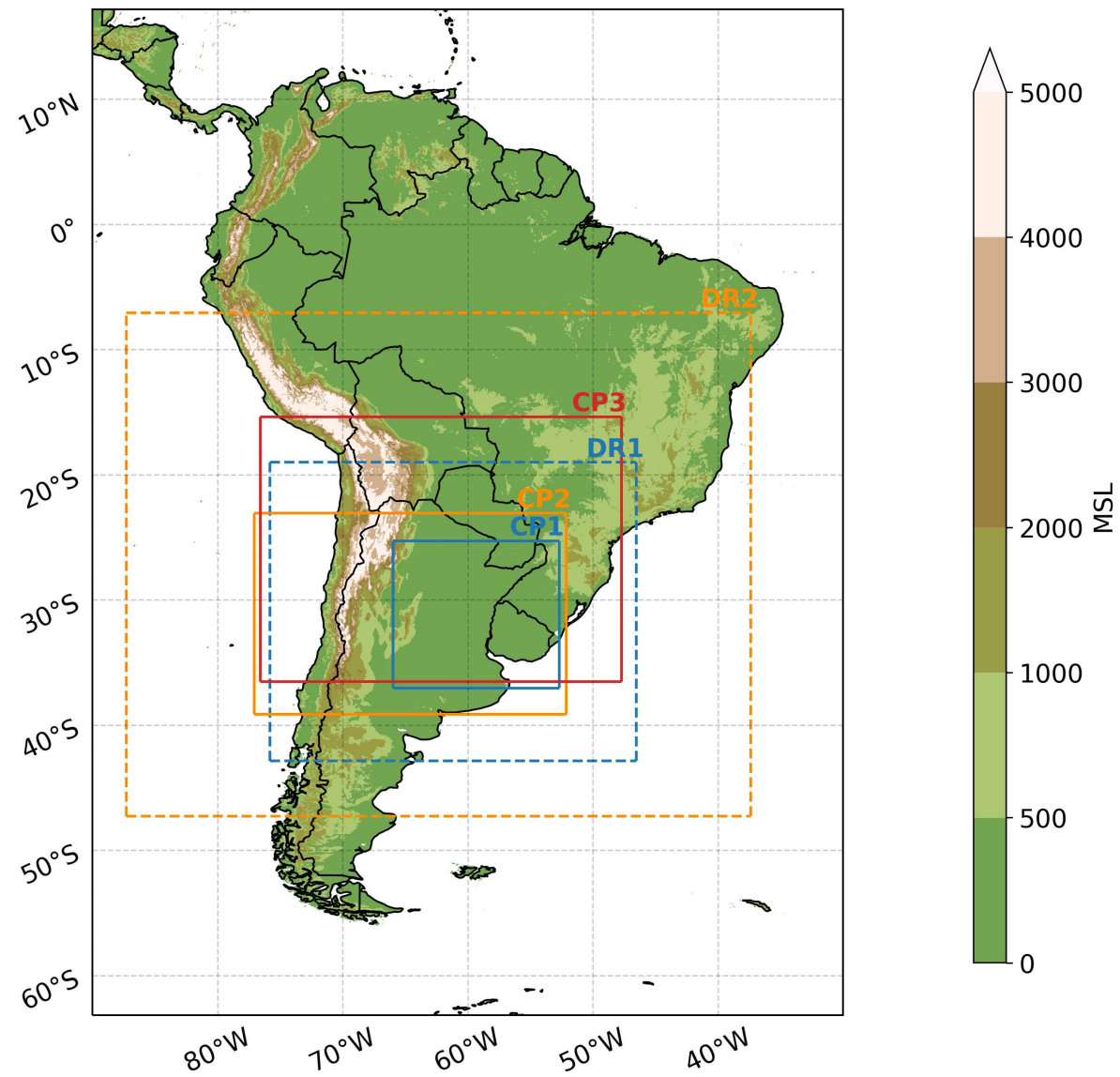

Fig. 1 Domain configurations of the WRF 3.9.1 simulations. Blue, orange and red squares indicate domains D1, D2 and D3, respectively. Dashed lines indicate the driving domain (DR) in the two-step nesting approach. Solid lines indicate the domain of the convection - permitting (CP) simulations

respectively. These CP simulations allow exploring to which extent the horizontal resolution of the $\mathrm{CP}$ domain matters. The CP1 simulations cover an area of approximately $13^{\circ} \times 12^{\circ}$ (longitude - latitude). Simulations performed at D2 differ from D1 in the size of the domain and also in the nesting strategy. For the twostep nesting configuration, not only the DR2 domain extends over a much broader area compared with DR1 allowing for a better representation of the large scale forcings entering the CP domain, but the western boundary of the CP2 simulation is located off the coast of Chile and hence, allowing for a proper interaction be- 
tween the inflow at that boundary and the complex Andes topography. Moreover, the CP2 domain includes the Sierras de Córdoba over central Argentina where convection usually starts (Rasmussen et al, 2016). Given the dominant role of the Andes in modulating the westerly flow and given the control that the Sierras de Córdoba exert on the triggering mechanisms for convective processes to initiate, this domain configuration allows exploring the relevance of including the main topographic features controlling the mechanisms associated with the occurrence of organized convection in SESA. The CP2 domain is implemented only at $4 \mathrm{~km} \quad{ }_{277}$ horizontal resolution, with roughly $280 \mathrm{~K}$ grid points and covers an area of ap- 278 proximately $25^{\circ} \times 16^{\circ}$. In order to explore the impact of the horizontal resolution ${ }_{279}$ in the two-step nesting configuration, DR2 was implemented at two horizontal 280 resolutions, $12 \mathrm{~km}$ and $20 \mathrm{~km}$, corresponding to barely $150 \mathrm{~K}$ and $55 \mathrm{~K}$ grid points. $\quad 281$ Additionally, one of the physics ensembles performed in the CP2 domain is driven $\quad{ }_{282}$ directly by the ERA-Interim reanalysis, hereafter referred to as the one-step nest- $\quad 283$ ing configuration. This experiment is designed to explore the nesting strategy, i.e. $\quad 284$ two-step vs. one-step nesting. This last set up also rises the issue of the spatial ${ }_{285}$ spin-up, since the resolution rate between the model providing the lateral bound- $\quad 286$ ary conditions (LBC) and the CP domain is close to 18 and hence, a large number $\quad 287$ of grid points close to the boundaries needs to be discarded to avoid introducing $\quad 288$ noise due to the resolution jump.

Finally, D3 is configured in a one-step nesting approach, similarly as one of 290 the experiments in the D2 set up, but with a larger domain, spanning $29^{\circ} \times 21^{\circ} . \quad 291$ The aim of exploring this domain is to enlarge the CP domain in order to capture $\quad{ }^{292}$ not only the extreme events but also the circulation driving the evolution of the ${ }_{293}$ events. Note that the CP3 domain is not only larger than the CP2 configured in 294 the one-step nesting approach, but its northern boundary is located up to $15^{\circ} \mathrm{S}, \quad 295$ allowing for better capturing the low-level northerly moisture flow -a key ingredient $\quad 296$ to develop deep convection. 
The experimental set up described above is also framed considering the trade- ${ }^{298}$ offs between domain configuration, including domain size, resolution and nesting 299 strategy, and computational costs. It is also worth recalling that the larger the 300 number of nesting steps the more the computational cost of the simulations.

The focus of this study is on evaluating the extent to which different model configurations capture extreme precipitation events together with their triggering forcing mechanisms. Hence, the analysis is centered on the main features of three precipitation events in terms of their intensity, location and temporal evolution and on the low-level circulation patterns, namely, the meridional component of the wind and the geopotential field at $850 \mathrm{hPa}$. Given the dominant role of the moisture flux convergence on the development of the extreme events over SESA (Lavín Gullón et al, 2021; Solman et al, 2021), the vertically integrated moisture flux for each of the selected events has also been evaluated. The analysis is focused on the lowlevel circulation since it is at the lower levels of the atmosphere where the regional forcings associated with topographical features may have the largest impact.

The skill of the models in representing the precipitation events is assessed with the Fractional Skill Score (FSS; Roberts and Lean, 2008). The FSS is a metric based on a neighborhood approach that measures how the simulation skill varies with the spatial scale at which simulations and observations are being compared. The FSS compares the observed and modeled fraction of grid points with precipitation above a certain threshold within a running square domain of varying size, ranging from a single grid cell to twice the size of the simulation domain. The FSS ranges from 0 to 1 , being 1 a perfect skill. Roberts and Lean (2008) defined a critical FSS that indicates the minimum value of FSS that should be reached for a skilfull prediction. The FSS is generally monotonically increasing with the spatial scale, hence, the smaller the scale at which the FSS equals the skilfull scale, the 
better the model performance, indicating that the model is able to capture the fractional precipitation occurring at smaller scales.

In order to account for the timing and intensity of the precipitation events, the FSS was calculated for each member of the ensemble against every observational dataset every 3 hours during the whole event. The minimum spatial scale at which the model is skillful is computed at each timestep. The precipitation threshold selected for the calculations of the FSS is the $95^{\text {th }}$ spatial percentile of the observed 3-hourly precipitation. Therefore, for each event, each ensemble member and each observational dataset, the minimum spatial scale was computed, and the distribution of the minimum skillful scale for every set of CPM simulation is represented in a box-plot.

Due to the FSS compares observed and simulated precipitation, every simulation and observational dataset was bilinearly interpolated onto a common grid of $0.1^{\circ} \mathrm{x} 0.1^{\circ}$. This resolution corresponds to the lowest resolution among the observational datasets. This interpolation implies an upscaling of the CPM simulations and, therefore, an apparent loss in high resolution information but it is still expected that high resolution information is transferred into the upscaled lower resolution domain (Torma et al, 2015; Fantini et al, 2018). This interpolation was also applied to adequately compare the synoptic and precipitation fields between the simulations and the datasets.

\section{Results}

In what follows an overview of the selected extreme precipitation events is pre- 346 sented. Then, the performance of the ensemble mean CPM simulations correspond- $\quad 347$ ing to the 6 model configurations (listed in Table 2) is assessed for each event in 348 terms of their capability in reproducing the spatial distribution of the maximum 349 3-hourly accumulated precipitation, the temporal evolution of the 3-hourly accu- 350 mulated precipitation during the onset, mature stage, and decay together with the 351 associated circulation features. 


\begin{tabular}{|c|c|c|c|c|c|c|c|c|c|}
\hline \multirow[b]{3}{*}{ P90 } & \multicolumn{3}{|c|}{$\begin{array}{c}\text { Case1 } \\
\text { 2005-03-12 }\end{array}$} & \multicolumn{3}{|c|}{$\begin{array}{c}\text { Case2 } \\
2015-11-10\end{array}$} & \multicolumn{3}{|c|}{$\begin{array}{c}\text { Case3 } \\
2016-10-24\end{array}$} \\
\hline & CMORPH & IMERG & MSWEP & CMORPH & IMERG & MSWEP & CMORPH & IMERG & MSWEP \\
\hline & 74 & 70 & 69 & 59 & 36 & 34 & 54 & 47 & 38 \\
\hline P95 & 124 & 105 & 112 & 86 & 70 & 51 & 75 & 72 & 52 \\
\hline P99 & 213 & 158 & 143 & 111 & 122 & 70 & 110 & 116 & 72 \\
\hline $\mathrm{A}+50$ & 26.4 & 22.4 & 20 & 18.8 & 11.3 & 7.8 & 16.5 & 13.2 & 8.1 \\
\hline
\end{tabular}

Table 4 Summary of the daily precipitation features of the selected individual events for each precipitation dataset. The three middle rows depict the spatial percentiles of the daily precipitation corresponding to the $90^{\text {th }}, 95^{\text {th }}$ and $99^{\text {th }}(\mathrm{mm} /$ day $)$ and the bottom row displays the approximate extension of the area $\left(x 10^{4} \mathrm{~km}^{2}\right)$ where the daily precipitation is above 50 $\mathrm{mm} /$ day.

3.1 Description of the selected events

Table 4 lists the dates of the selected extreme events together with some specific features, such as extreme spatial percentiles of the daily precipitation and the area covered with precipitation above $50 \mathrm{~mm}$ /day as depicted by each of the datasets listed in Table 1 . Case 1, occurring on March $12^{\text {th }}, 2005$, is the most intense event as denoted by the spatial $99^{\text {th }}$ percentile of the daily rainfall ranging between 143 $\mathrm{mm} /$ day to $213 \mathrm{~mm} /$ day, depending on the dataset. Inspection of the 3-hourly precipitation of all datasets (not shown) revealed that the event initiated at around 18 UTC on March $11^{\text {th }}$ east of the Andes Mountain range, progressed eastwards reaching the peak precipitation at 06 UTC on March $12^{\text {th }}$ and further propagating northeastward while acquiring a northeast-southwest band shape. This is the typical behavior of MCS in SESA according to the literature (Rasmussen and Houze, 2016; Matsudo and Salio, 2011; Romatschke and Houze, 2013). Figure 2 shows 365 the 3-hourly peak precipitation for the Case 1 event. Satellite estimates (Fig. 2 a, 366 $\mathrm{d}$ and $\mathrm{g}$ ) display two maximums, with the largest peak rainfall ranging from $45 \quad 367$ $\mathrm{mm}$ to above $100 \mathrm{~mm}$ centered on $31^{\circ} \mathrm{S} 61^{\circ} \mathrm{W}$ and a secondary peak located to ${ }_{368}$ the northwest. The discrepancies among datasets in terms of the intensity of the 369 peaks are remarkable.

Case 2 started at 18 UTC on November $9^{\text {th }} 2015$, progressed eastwards reaching $\quad 371$ the peak precipitation at 06 UTC on November $10^{\text {th }}$ over northeastern Argentina 372 close to the border with Brazil and propagated further eastward during its decline $\quad 373$ 


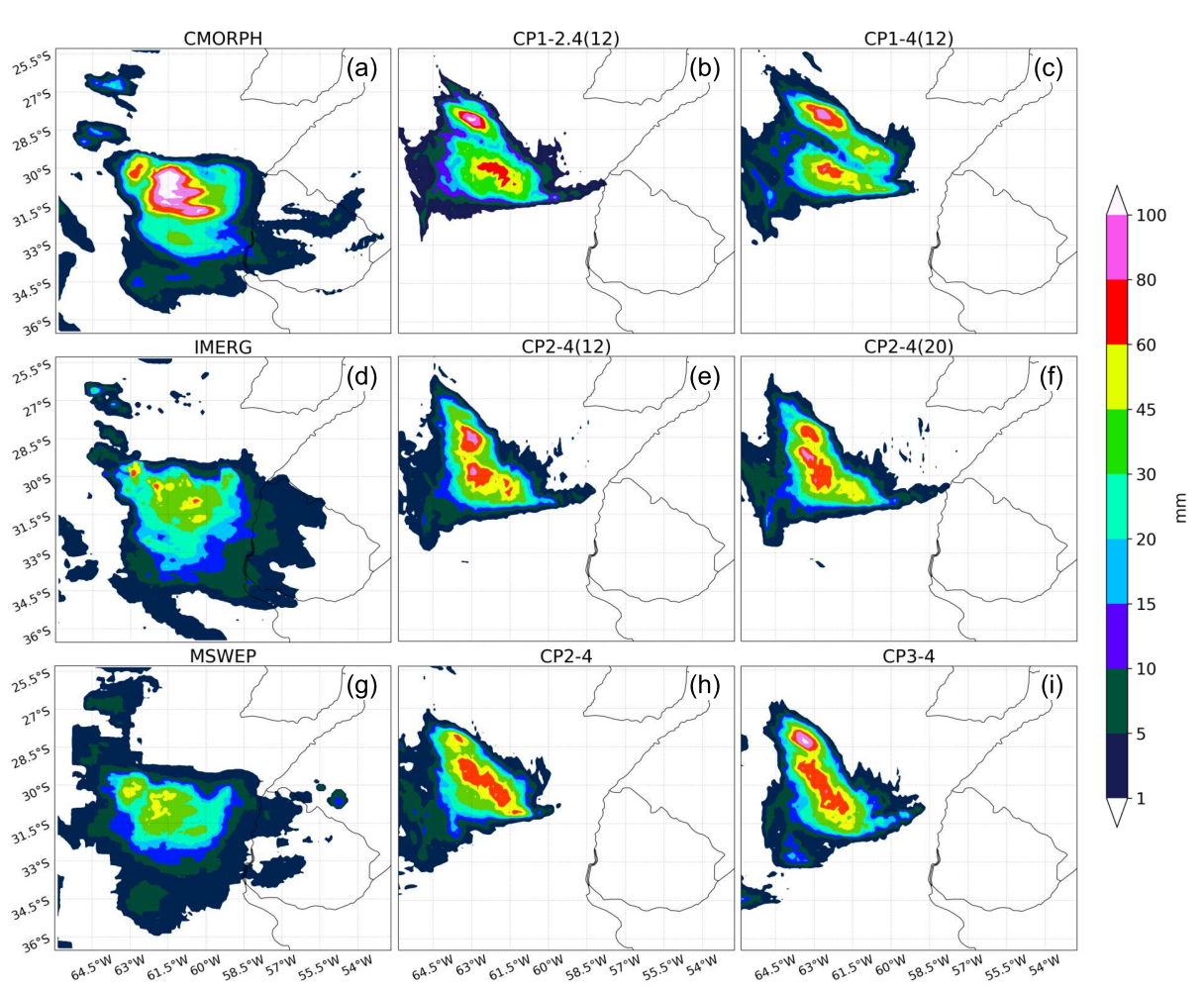

Fig. 2 Maximum 3-hourly precipitation for Case 1 ( $\mathrm{mm}$ ). Left panels (a, d, g) display the observational datasets. Central and right panels display the ensemble mean of CPM simulations listed in Table 3.

(not shown). The spatial $99^{\text {th }}$ percentile of the daily rainfall during the day of 374 maximum rainfall ranges from 70 to $111 \mathrm{~mm} /$ day, as depicted by the 3 datasets 375 (Table 4). Peak 3-hourly precipitation displayed in figure 3 shows that the peak 376 3-hourly rainfall (e.g. above $60 \mathrm{~mm}$ ) is very localized over a small region centered 377 at roughly $28.5^{\circ} \mathrm{S} 56^{\circ} \mathrm{W}$, though the area with heavy rainfall extends over a much broader region, as depicted by every dataset. A less intense precipitation system is also apparent to the southwest of the main peak. The agreement in the spatial distribution of rainfall at the time of the maxima among the three datasets is apparent.

Case 3 started during nighttime hours, around 00UTC and 03 UTC on October $38424^{\text {th }} 2016$ and reached the peak precipitation intensity at 09 UTC on October $38524^{\text {th }}$, being a more explosive event compared with Cases 1 and 2 (not shown). The 


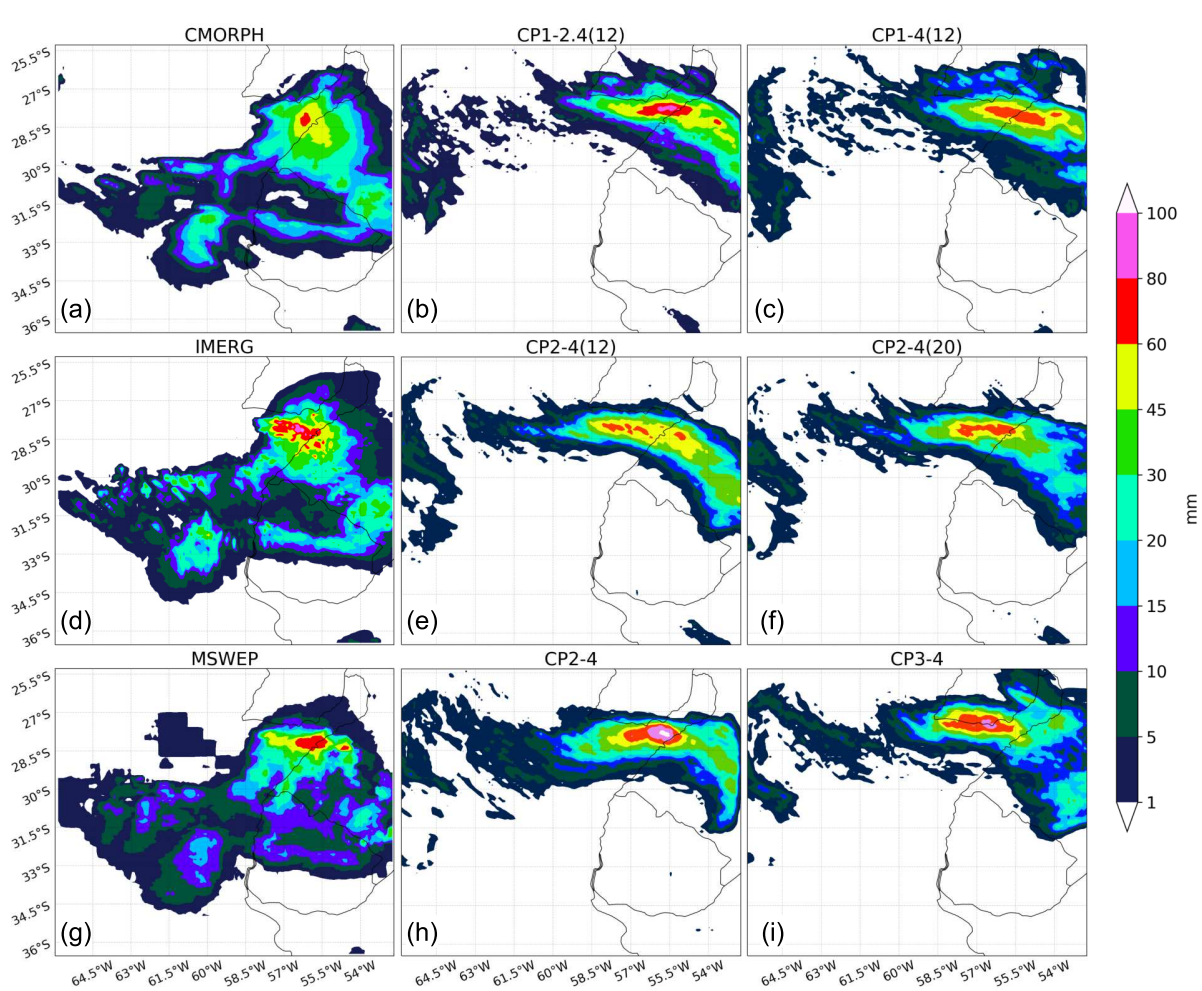

Fig. 3 Same as Fig. 2 but for Case 2.

maximum 3-hourly rainfall for this event displayed in Figure 4 depicts a localized area with peak intensity centered around $29^{\circ} \mathrm{S}, 59^{\circ} \mathrm{W}$ and a secondary peak further to the west. Additionally, a secondary system developing over the southwestern corner of the domain is also apparent. The observations encompass a wide range of rainfall intensities at the time of the maximum peak, but every dataset agrees on the location and spatial extent of the precipitation maximum. This event is characterized by a much more localized system which may represent a challenge in terms of model performance. A relevant feature of this event is that heavy rainfall started at night hours (21hs to 00hs local time) while the other two events started 394 in the afternoon and reached the peak during early morning hours, in agreement 395 with the typical diurnal cycle of extreme rainfall events developing in the region 396 (Rasmussen et al, 2016). 


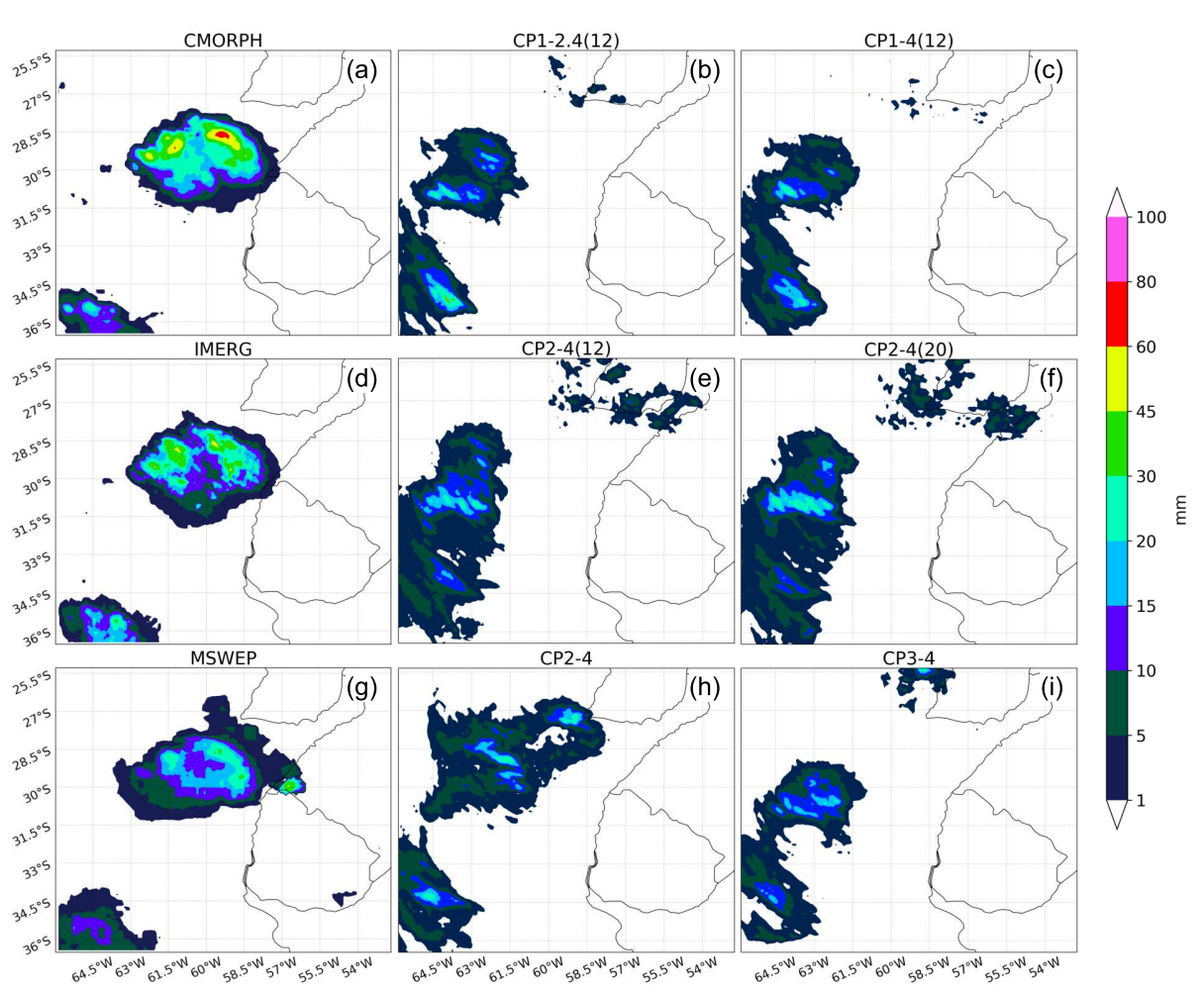

Fig. 4 Same as Fig. 2 but for Case 3.

The discrepancies in the precipitation intensity among datasets for the three extreme events emerge clearly from Table 4 and figures 2, 3 and 4, with CMORPH showing the highest values and MSWEP showing the lowest values. The spread 400 in the precipitation amount among datasets increases with the spatial percentile, $\quad 401$ revealing the difficulties of the satellite estimates to reproduce extreme precipita- $\quad 402$ tion. The observational uncertainty associated with extreme rainfall events arises $\quad{ }_{403}$ clearly in this analysis. It represents a serious obstacle for assessing model perfor- $\quad 404$ mance, given that the assessment of model performance will strongly depend on 405 the observational dataset used. 
3.2 Simulated precipitation

A comparison of the peak 3-hourly accumulated precipitation between the set of $\quad 408$ CP experiments (Table 3) and observations for each individual event is displayed 409

in Figures 2, 3 and 4, respectively. $\quad 410$

For Case 1, Figure 2 shows that all CP simulations broadly capture the event, ${ }^{411}$ though there are some differences among the set of model configurations. First, ${ }_{412}$ all simulations display the core of the event slightly shifted towards the northwest $\quad{ }_{413}$ compared with the observations. The maximum intensity is similarly represented $\quad{ }_{414}$ by every $\mathrm{CP}$ simulation, but it is difficult to identify the extent to which the sim- $\quad 415$ ulations are overestimating or underestimating the peak given that the maximum $\quad{ }_{416}$ intensity from the set of observations is quite dissimilar. If we compare the two ${ }_{417}$ two-step nesting simulations for the D1 domain, the $2.4 \mathrm{~km}$ resolution ensemble CP1-2.4(12) against the $4 \mathrm{~km}$ resolution ensemble CP1-4(12), (Fig. 2b and c), the differences are quite subtle, suggesting that for this individual event the resolution of the CP model does not have a strong impact on the quality of simulated precipitation. Enlarging the domains (D2 vs D1) does not translate into any significant impact (Fig. 2c vs e), nor does the horizontal resolution of the driving domain (Fig. 2e vs $\mathrm{f}$ ). The location and spatial extension of the system is sensitive to the nesting strategy (Fig. 2e vs h) though only for the larger CP domain (Fig. 2i) the system seems to be better reproduced. In this CP ensemble (CP3-4) the system extends to the southeast, in a better agreement with the observations, and the unrealistic rainfall close to the western boundary that is present in all the other CPM configurations, is not simulated.

For Case 2 (Fig. 3) every simulation captures the core of the peak precipitation in terms of both location and intensity, though the spatial extension of the system is restricted to a smaller area compared with the observations. No simulation reproduces the broader area with intense rainfall extending over the central part of the domain. The event develops too close to the eastern boundary in the CP domains D1 and D2, suggesting that these domains may be too small for simulating 
extreme events in SESA that may develop over a broader area extending further east. Moreover, the one-step nesting ensemble over domain D3 (Fig. 3i), CP3-4, is the only simulation reproducing the secondary maximum rainfall over southern Brazil, though it still fails in capturing the overall rainfall spatial distribution. As was noted for Case 1, no remarkable differences are found between the $2.4 \mathrm{~km}$ and the $4 \mathrm{~km}$ resolution $\mathrm{CP} 1$ ensembles (Fig. $3 \mathrm{~b}$ vs c). The peak rainfall seems to cover a smaller area for the CP2 ensembles compared with CP1, suggesting that enlarging the CP domain towards the west does not have a systematic impact on improving the quality of the simulated rainfall. Additionally, the one-step nesting over the D2 domain (CP2-4) does not display any important difference compared with the two-step nesting simulation (either CP2-4(12) or CP2-4(20)).

For Case 3 (Figure 4) every CP simulation fails in reproducing the core of the event at the right location, but a center of rainfall above $15 \mathrm{~mm}$ located further to the west, at $63^{\circ} \mathrm{W}$, is apparent. Only the one-step nesting $\mathrm{CP}$ simulation over the D2 domain, CP2-4 (Figure 4h) reproduces a rainfall center in a better agreement with the observations. As for Cases 1 and 2, no differences can be highlighted between $\mathrm{CP}$ simulations at different resolutions. Results are sensitive to the size of the domain (e.g. D1 vs D2) though no improvement in the quality of the CP simulations is apparent in the two-step nesting experiments when a larger domain is used (middle row vs top row).

The misrepresentation of the peak precipitation for some of the selected events analyzed may be due to either the CP simulations fail in reproducing the event or they fail in reproducing its temporal evolution. In order to explore the capability of the $\mathrm{CP}$ simulations in reproducing the temporal evolution of the systems, Figures 5 display the time-series of the spatially averaged 3-hourly accumulated rainfall. Large differences are found among the three different observational datasets, with $\quad 461$ CMORPH systematically overestimating IMERG and MSWEP datasets. Though ${ }_{462}$ there is an overall agreement on the temporal evolution of each event among the $\quad{ }_{463}$ three datasets, CMORPH depicts some inconsistencies on the time of the day ${ }_{464}$ 
of the precipitation peak, compared with IMERG and MSWEP. It is worth to ${ }_{465}$ recall that both IMERG and MSWEP are blended with station data, hence, they ${ }_{466}$ probably agree better with station data in terms of the timing of the events than $\quad 467$ CMORPH. All CP simulations adequately capture the onset, the peak and the ${ }_{468}$ decay of the three extreme events, with some subtle differences in the intensity ${ }_{469}$ of the maximum peak and to a lesser extent in the time of the day when the 470 maximum rainfall is simulated. Overall, no systematic differences among the 6 CP $\quad 471$ ensembles are apparent. For Case 1, the development of a secondary system after $\quad 472$ the decay of the main event is apparent from the observations. However, the CP ${ }^{473}$ simulations produce a weaker event peaking three hour later. After the decay of ${ }_{474}$ the following day is well reproduced. Note that this event has a much smaller spatial scale compared with Cases 1 and 2 and hence, it may be more difficult to be adequately simulated.

Overall, the higher the spatial resolution in the CP simulations for domain D1 the larger the intensity of the peak rainfall, consistent with the literature (e.g. Li et al, 2019; Fosser et al, 2014). This is due to that higher resolution CP simulation produces more localized cells with larger precipitation intensity (not shown). The spread among members of each CP ensemble is systematically larger when the rainfall intensity is higher. Considering that the $\mathrm{CP}$ ensemble members differ in the microphysics schemes, the planetary boundary layer schemes and the treat- ${ }^{492}$ ment of the shallow convection, this is expected since the processes involved exert a 

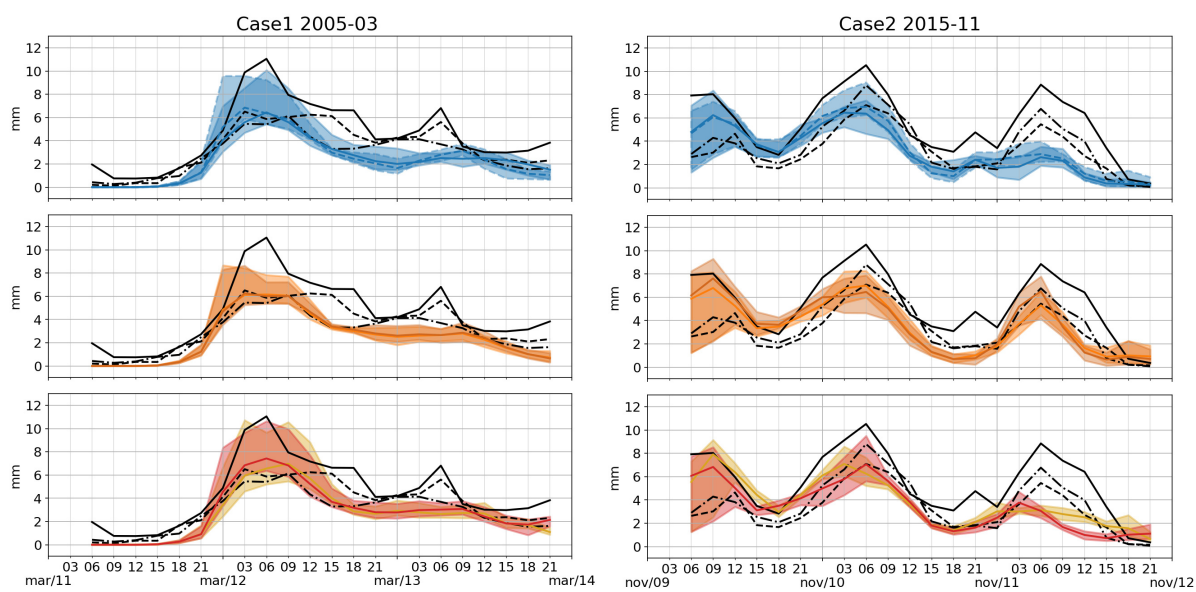

Case3 2016-10
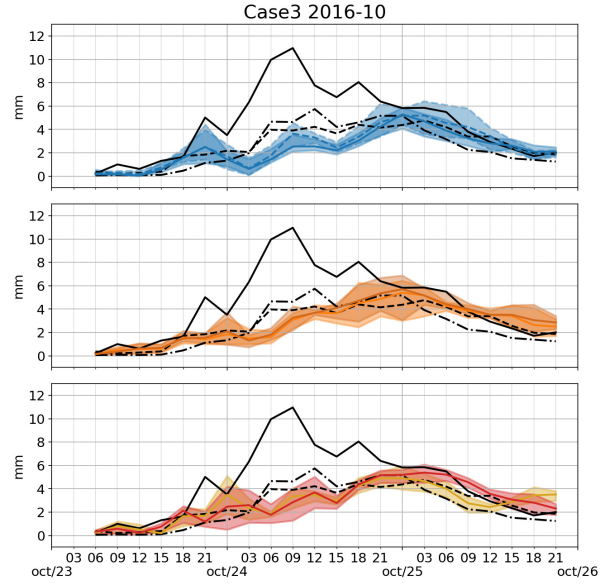

Fig. 5 Time-series of the 3-hourly accumulated rainfall averaged over the target area for Case 1 (left column), Case 2 (central column) and Case 3 (right column). The ensemble mean (lines) and the ensemble spread among members of CP simulations (shaded) are displayed for the two-step nesting CP simulations at the D1 domain (top), the two-step nesting CP simulations at the D2 domain (middle) and the two one-step nesting simulations over D2 and D3 (bottom), respectively.

strong impact on how convection is triggered and on the hydrometeors, and hence, core extreme event, the spread among members is lower for the one-step nesting simulations. This feature is particularly important when considering CP simulations covering longer periods, since reducing the uncertainty of the simulations is

a key challenge. 

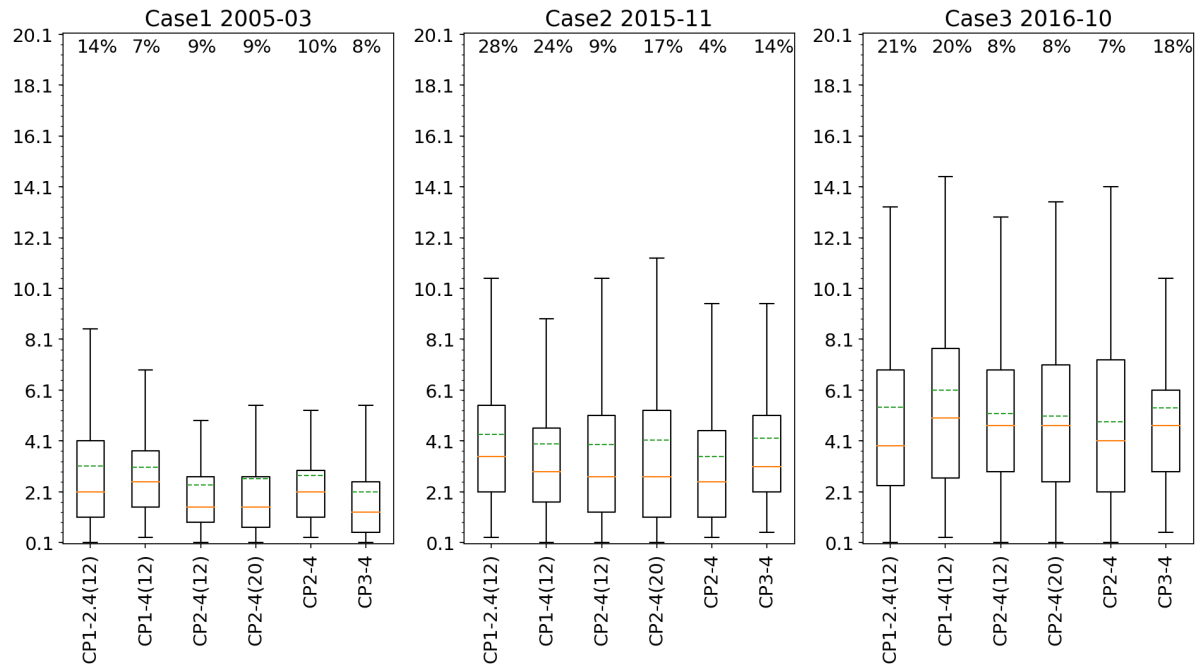

Fig. 6 Boxplot of the minimum spatial scale at which each CP ensemble is skillful. The horizontal axis indicates the CP ensembles, and the vertical axis indicates the minimum spatial scale. The boxes and whiskers are built from the information derived from the FSS computed every 3 hours against each of the three observational datasets and for each of the 6 members of the ensemble. The numbers in the upper part of each boxplot represent the percentage of times in which the FSS score does not reach a skillful value. The orange and green lines indicate the 50th percentile and the mean value of the minimum spatial scales, respectively. The boxes delimit the 25 th and 75 th percentiles and the whiskers denote the 5 th and 95 th percentiles.

The evaluation based on the spatial distribution of the peak rainfall and on the temporal evolution of the events is limited due to part of the information characterizing the extreme events may be missing. It is important to assess the capability of the CP simulations in capturing the timing, the intensity and the location where precipitation occurs. Accordingly, and to provide a more quantitative measure of the quality of the set of CP simulations, the FSS score is evaluated. The minimum spatial scale at which the FSS reaches a skillful value is obtained along the life cycle of each event for each ensemble member, computed against each of the three observational datasets. Figure 6 shows a box-plot of the minimum skillful spatial scale at which each simulation captures the fractional 3-hourly precipitation for each event. The lower the spatial scale, the better the CPM performance.

As found in the previous analysis, increasing the spatial resolution of the $\mathrm{CP}$ ensemble does not always imply better model performance. The $2.4 \mathrm{~km}$ resolution CP1 ensemble does not display systematic smaller skillful spatial scales compared 

of the driving domain does not impact on the capability of the CP ensemble in capturing the peak of the events. This result arises when comparing the $4 \mathrm{~km} \mathrm{CP}$ ensemble nested in either the $12 \mathrm{~km}$ or the $20 \mathrm{~km}$ driving model over the domain D2 (CP2-4(12) vs CP2-4(20)). Again, this outcome has important implications in terms of computational costs. However, when the size of the domain is enlarged (e.g., the $4 \mathrm{~km} \mathrm{CP}$ ensemble over D1 vs the $4 \mathrm{~km} \mathrm{CP}$ ensemble over D2), the CP ensemble displays smaller skillful spatial scales, suggesting that the domain size of the CP simulation does have an impact on the capability of the model in capturing the events. This is particularly evident for Cases 1 and 3. This is an expected result given that the D2 nested simulations can better capture the triggering mechanisms associated with the topographic forcing compared with the CP ensemble in the D1 domain. Concerning the nesting strategy, the one-step nesting displays a clear improvement compared with the two-step nesting for Cases 2 and 3 in terms of reducing the skillful spatial scales (e.g., comparing the $4 \mathrm{~km} \mathrm{CP}$ ensemble driven by either the $12 \mathrm{~km}$ or the $20 \mathrm{~km}$ resolution $\mathrm{RCM}$, referred to as CP2-4(12) and CP24(20), vs the $4 \mathrm{~km} \mathrm{CP}$ ensemble driven by the reanalysis, referred to as CP2-4). Enlarging the CP domain in the one-step nesting approach translates in a better ${ }_{538}$ model performance, particularly for Case 1. For Cases 2 and 3 the CP3-4 ensemble 539 displays a smaller spread among ensemble members. Furthermore, given that one- $\quad 540$ step nesting simulations involve only one domain, in terms of computational costs 541 they result cheaper than the two-step nesting approach. In fact, comparing the $\quad 542$ 
computational resources used to perform the CP2-4 (12) simulations against the ${ }^{543}$ CP2-4 simulations, the latter was roughly $30 \%$ cheaper.

\subsection{Synoptic forcings}

As already mentioned earlier, extreme precipitation events in SESA are mostly associated with organized deep moist convection (Rasmussen et al, 2016). Isolated convective cells usually initiate during the afternoon hours on the east side of the Andes and the Sierras de Córdoba hills located over central Argentina. These systems propagate further eastward and develop into organized convective systems

in the presence of the South American low-level Jet (SALLJ). The SALLJ is a northerly wind that advects warm moist air from the Amazon forest into subtropical latitudes (Salio et al, 2007). The SALLJ penetration into higher latitudes together with a mid-to-upper-level subsidence in the lee side of the Andes, that caps the low-level flow inhibiting the convection close to the Andes, represent the key ingredients for upscaled convective systems developing over SESA. Furthermore, the cyclone formation on the lee side of the Andes is another important feature of convection initiation, enhancing northerly flow and favoring a strong moisture flux convergence that fuels long-lived MSCs over SESA (Rasmussen and Houze, 2016; Salio et al, 2007). Hence, the evolution of MCSs in SESA is highly influenced by the SALLJ and by the low-level circulation pattern. Therefore, we focus on evaluating how the main synoptic forcing mechanisms described above are captured by the set of CP ensembles. Due to the CP ensembles being short-term simulations lasting for 72-hours, it is not expected that the mid and upper-level circulation features diverge from the driving reanalysis, hence, the analysis is fo- $\quad 565$ cused on the low-level circulation features at $850 \mathrm{hPa}$. As shown in Solman et al 566 (2021), the location of the exit region of the low-level jet and of the moisture flux 567 convergence largely determines the area where the maximum precipitation occurs $\quad 568$ during the subsequent hours. Hence, Figures 7, 8 and 9 display the $850 \mathrm{hPa}$ cir- $\quad 569$ culation together with the vertically integrated moisture flux 6 hours before the 570 


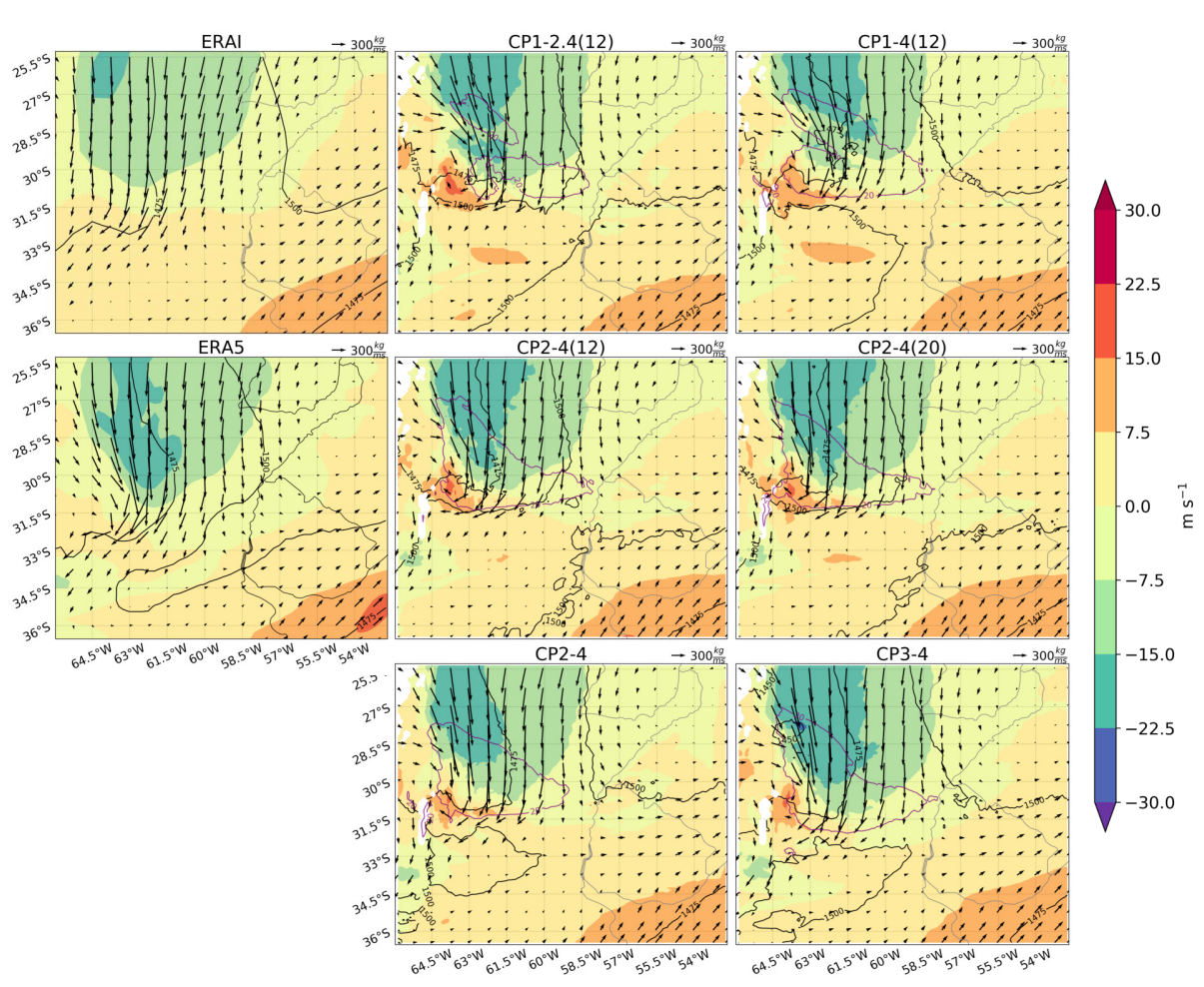

Fig. 7 Vertically integrated moisture flux (vectors), 850hPa geopotential height (black contours) and intensity of the meridional component of the wind at 850hPa (shaded) 6 hours before the peak precipitation occurs for Case 1 . Purple lines display the $20 \mathrm{~mm}$ contour of the maximum 6-hourly accumulated precipitation. The two top left panels are from ERA-Interim and ERA5, respectively. The rest of the panels display the ensemble mean for each of the 6 CP ensembles.

maximum rainfall rate occurs for Cases 1,2 and 3, respectively, as depicted by the reanalysis and the $\mathrm{CP}$ ensemble simulations. It is interesting to highlight that 572 for the three events, the ERA5 reanalysis depict important differences compared 573 with the ERA-Interim dataset in terms of the intensity and southward penetra574 tion of the low-level jet and in the spatial configuration of the moisture flux. These differences may be associated with the spatial resolution of the two reanalyses

For Case 1 (Fig. 7), the ERA5 reanalysis shows a strong southward meridional flow with intensities above $15 \mathrm{~m} / \mathrm{s}$, which provides the moist and warm conditions over the target region. The moisture flux penetrates southward with the area of maximum convergence located over the area where the maximum rainfall core is observed (Fig. 2), roughly around $31^{\circ} \mathrm{S} 61.5^{\circ} \mathrm{W}$. As indicated above, the ERA- 


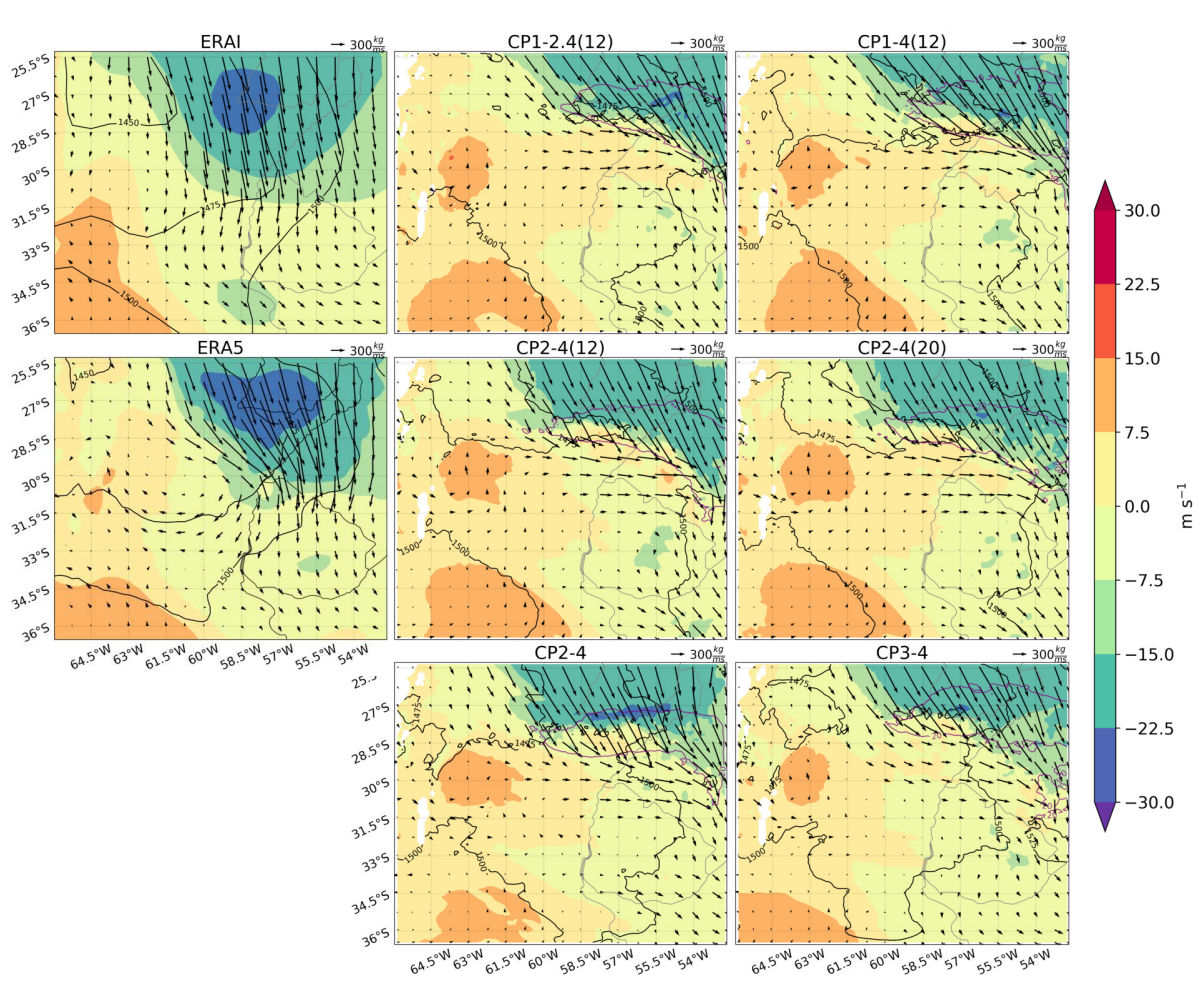

Fig. 8 Same as Fig. 7 but for Case 2 . respect to the $\mathrm{CP}$ simulations and the observations (not shown). The two CP 592 ensembles for the D1 domain, CP1-2.4(12) and CP1-4(12), display quite similar $\quad 593$ results. This is expected given that the $\mathrm{CP}$ domain extends over a $12^{\circ} \mathrm{x} 13^{\circ}$ (lon-lat) 594 


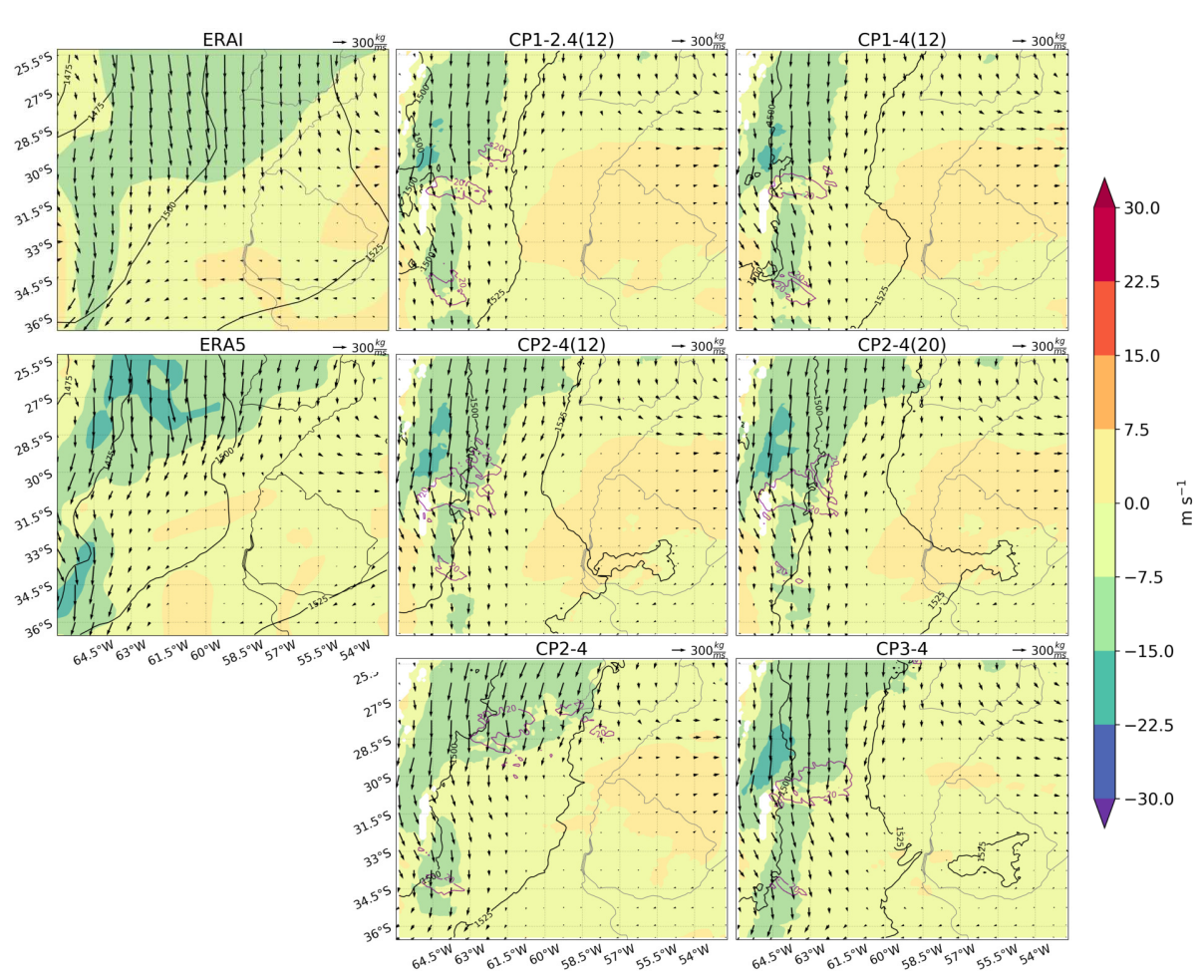

Fig. 9 Same as Fig. 7 but for Case 3. The maximum precipitation for this event occurs at a time not available for ERA-Interim, hence, the synoptic drivers correspond to 3 hours later than the rest of the panels.

region mostly over a flat area, being the western boundary too close to the Sierras de Córdoba, hence, the topography either at $2.4 \mathrm{~km}$ or $4 \mathrm{~km}$ resolution, is not able to modulate the flow within the $\mathrm{CP}$ domain. Enlarging the $\mathrm{CP}$ domain towards the 597 west (the D2 domain), where the main topographic systems that exert an impact on the initiation of convection are included, does not display any strong impact on the simulated circulation either. Similarly, the two two-step nesting simulations for the D2 domain, CP2-4(12) and CP2-4(20), are very similar, independently of ${ }_{601}$ the resolution of the driving domain. The one-step nesting CP ensembles in any ${ }_{602}$ of the two domains, CP2-4 and CP3-4, display a better agreement with the ERA5 603 reanalysis in terms of the southward penetration of the low level jet and in the ${ }_{604}$ location of its exit region, being the $\mathrm{CP}$ ensemble over the D3 domain (CP3-4) the $\quad{ }^{605}$ one that better captures the moisture flux convergence, the location of the cyclonic $\quad 606$ 
circulation close to the western boundary and the location of the exit region of the $\quad 607$ low level jet. This is consistent with the better agreement with the observations ${ }^{608}$ of the CP3-4 ensemble in terms of the location of the core of the rainfall event ${ }_{609}$ mentioned previously.

For Case 2 (Figure 8) both, the ERA5 and the ERA-Interim reanalysis dis- ${ }_{611}$ play the exit region of the low-level jet and the convergence of the moisture flux ${ }_{612}$ over the region where the maximum rainfall is observed (see Fig. 3), with ERA5 ${ }_{613}$ depicting more intense meridional wind and moisture flux and the presence of a 614

cyclonic circulation to the west of the rainfall maximum, which is not apparent in the ERA-Interim reanalysis. This circulation is important due to it enhances the northwesterly flow and modulates the moisture flux convergence. Every CP ensemble captures this cyclonic circulation though shifted to the southeast compared with ERA5, affecting where the convergence of the moisture flux occurs and hence where the maximum precipitation is simulated. For all CP ensembles the moisture flux is deflected eastwards and the area of moisture flux convergence is located further to the north compared with ERA5, consistent with the location of the rainfall core. Note also that for domains D1 and D2 the system develops too close to the northern boundary, suggesting again, that these domains may be too small to capture systems developing within SESA. All CP ensemble simulations depict very similar circulation patterns, which explains their agreement in the representation of the extreme rainfall event. The performance of the $\mathrm{CP}$ simulations in capturing this event seems to be strongly conditioned by the quality of the driving reanalysis.

For Case 3 (Figure 9) differences between the two reanalyses in terms of both the intensity of the low-level jet and the moisture flux field are remarkable. The location of the core rainfall event (Fig. 4) agrees better with the exit region of the low-level jet and with the region where moisture flux converges in the ERA5 rather than the ERA-Interim reanalysis. Moreover, all CP ensemble simulations agree better with the ERA5 than with the ERA-Interim. For CP ensembles over D1, the 

rainfall event is also shifted westwards compared with the observations. As noted previously when evaluating the simulated precipitation patterns, the differences between the two two-step nesting CP ensembles for domain D2 are negligible, suggesting that the spatial resolution of the driving domain does not exert a strong influence on the CP simulation. The one-step nesting CP ensemble for the D2 domain (CP2-4) arises as the simulation that best captures the circulation compared with ERA5. Note that this simulation arose also as the one with the best performance in reproducing the location of the extreme rainfall event (Fig. 4). However, the pattern of the moisture flux over the target domain in the CP3-4 ensemble agrees better with the pattern depicted by ERA5 than any other CP ensemble. This may be related with the extension of the CP3-4 domain, which allows representing better the inflow over the northern part of the domain, given that the northern boundary is located at $15^{\circ} \mathrm{S}$ and hence, it captures the interaction between the northerly flow and the topography over Bolivia and northwestern Argentina, which deflects the low-level jet towards SESA.

Overall, it is apparent that every CP ensemble simulates the core of the rainfall event at the exit region of the low-level jet, where the moisture flux converges. This behavior suggests that, if the CP simulation is able to capture the synoptic scale 662 forcings that provide the environmental conditions for deep moist convection to 663 develop, they are also able to capture the rainfall event. The CP simulations over 
the D2 and the D3 domains, either the two-step nesting or the one-step nesting ${ }_{665}$ $\mathrm{CP}$ ensembles, arise as those with better performance in terms of simulating both $\quad{ }_{666}$ the synoptic-scale forcings and the extreme precipitation events, compared with ${ }_{667}$ the smaller CP domain (D1).

Concerning the nesting strategy, it is important to recall that multiple nestings $\quad{ }_{669}$ may deteriorate the quality of the CP simulations due to errors inherited from one $\quad 670$ driving domain to another (Brisson et al, 2015), besides of being computation- ${ }^{671}$ ally more expensive. On the other hand, the resolution jump between the model 672 providing the LBCs and the driven CPM, which is close to 18 for the CP2-4 and CP3-4 simulations, determines the spin-up distance within the nested domain, i.e., the extension of the area close to the lateral boundaries that should be discarded. As discussed by Matte and Lucas-Picher (2017), the spatial spin-up depends on the spatial resolution of the LBC. These authors suggested that the larger the resolution jump the larger the number of grid points that should be discarded from the analysis in the nested domain. Hence, considering the tradeoffs between the one-step versus the two-steps nestings, and in order to objectively assess the convenience of one strategy over the other, the RMSE of the geopotential height at $850 \mathrm{hPa}$ computed against the reanalysis has been evaluated for the CP ensembles along the length of the simulated period for each case. The RMSE has been computed within the common CP2 domain considering the DR2-12, CP2-4(12), CP2-4 and CP3-4 ensembles against both ERA-Interim and ERA5. A region extending $2.25^{\circ}$ away from the boundary of the CP2 domain has been discarded to account for the spatial spin-up. Each simulation has been interpolated to the grid of the reanalysis to which it is being compared $\left(0.25^{\circ} \mathrm{x} 0.25^{\circ}\right.$ for ERA5 and $0.75^{\circ} \mathrm{x} 0.75^{\circ}$ for ERAI). Similar results were obtained for ERA-Interim, with slightly higher ${ }_{689}$ values of RMSE, so Figure 10 displays the RMSE against ERA5 after discarding $\quad{ }_{690}$ the temporal spin-up time (6 hours). All CP simulations displays smaller errors ${ }^{691}$ compared with the DR2 ensemble simulation, indicating the added value of the ${ }_{692}$ CP simulations. However, the one-step nesting simulations depicts smaller RMSEs $\quad{ }_{693}$ 


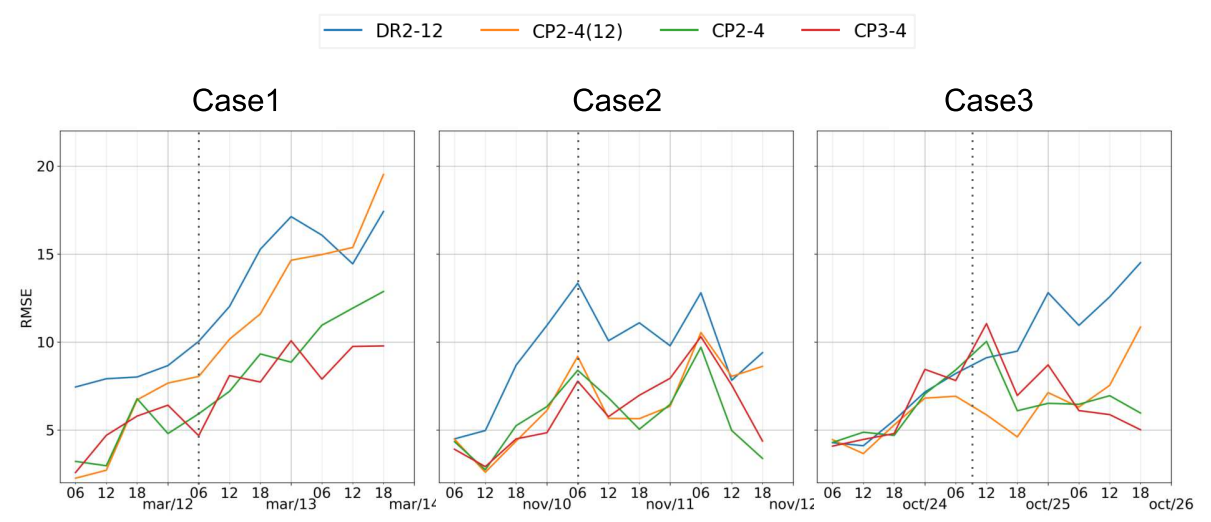

Fig. 10 Temporal evolution of the RMSE (m) computed for the 850hPa geopotential height against the ERA5 reanalysis for Cases 1, 2 and 3 (left, central and right columns, respectively). Vertical dashed lines denote the time of the maximum rainfall. Blue for DR2-20, orange for CP2-4(20), green for CP2-4 and red for CP3-4.

compared with the two-step nesting CP simulation for Case 1. Case2 shows similar

RMSE for both the one-step and two-step nesting simulations, while Case3 shows 
4 Summary and conclusions

This study explores a variety of modeling strategies for performing convection- 712 permitting simulations over Southeastern South America. The aim of the study is ${ }_{713}$ to identify the most suitable model configuration for reproducing the evolution of $\quad 714$ extreme rainfall events and their triggering mechanisms at a feasible computational $\quad 715$ cost. For that purpose, a set of 6 experiments focused on exploring the choice of the $\quad 716$ nesting strategy, the spatial resolution and the domain size were performed based 717 on short-term simulations lasting 72 hours using the WRF 3.9.1 model for three extreme precipitation events. For each of the selected cases, a 6-member physics ensemble was built in order to account for model uncertainty. All simulations were driven by the ERA-Interim reanalysis dataset.

The evaluation of the set of experiments is focused on the temporal evolution and spatial distribution of rainfall against a set of satellite-based precipitation observations. Including a set of observations allows acknowledging the observational uncertainty which is particularly large for extreme events in the target region. Additionally, given the strong control of the synoptic circulation during the early stages of the development of the events, the synoptic forcings were also evaluated against two different reanalyses: ERA-Interim and ERA5. The analysis based on individual events contributes to better understanding the mechanisms that may explain model deficiencies.

Several research questions drove this study. The question concerning the need of improving the resolution of the convection-permitting simulations was addressed by comparing the two-step nesting CP ensemble at $2.4 \mathrm{~km}$ resolution against a $4 \mathrm{~km}$ resolution for a $\mathrm{CP}$ domain spanning an area of $13^{\circ} \mathrm{x} 12^{\circ}$ (lon-lat). No significant differences were found between these two sets of experiments in terms of their capability in reproducing the main features of the extreme events together with the structure of the meridional flow at $850 \mathrm{hPa}$, the moisture flux convergence and the low-level circulation patterns. Additionally, the two-step nesting $2.4 \mathrm{~km}$ resolution $\mathrm{CP}$ ensemble required 3,5 times the computational resources of the two-step 

subtle differences in the performance of the CP ensembles, shown in terms of the smaller minimum spatial skillful scales found for the CP2-4(12) compared with the CP2-4(20) ensembles. This may be due to the fact that no relevant differences arise when the horizontal resolution of the driving domain increases from 20 to $12 \mathrm{~km}$. A significant improvement in the quality of the $\mathrm{CP}$ ensemble was found when enlarging the $\mathrm{CP}$ domain size from the $13^{\circ} \times 12^{\circ}$ (lon-lat) to the $25^{\circ} \times 16^{\circ}$, referred to as CP1-4(12) and CP2-4(12), respectively. The major difference between these two domains is the position of the western boundary, which is located over the eastern Pacific Ocean, i.e. shifted to the west in the CP2 domain compared with the CP1 domain. This improvement is apparent in the simulated precipitation and in the synoptic circulation triggering the extreme events. This result was expected given the relevant role of the Andes and the Sierras de Cordoba topographic features in the initiation of convection, given the environmental favorable conditions that fuels the subsequent eastern progression and upscale of the systems. Hence, it is recommended that convection-permitting simulation for SESA should be performed over a domain that extends westwards at least over the eastern Pacific Ocean to include the topographic forcing which triggers convection and modulates the synoptic scale circulation.

Concerning the nesting strategy, a two-step nesting approach was compared 766 with a one-step nesting approach in which the CP simulations were driven di- $\quad 767$ rectly by the reanalysis. Additionally, the one-step nesting was implemented for 768 
two domain sizes, extending over a $25^{\circ} \times 16^{\circ}$ lon-lat box and over a larger area 769 $\left(29^{\circ} \times 21^{\circ}\right)$. In the latter, the northern boundary is shifted further to the north 770 with the aim of including the area where the low-level jet reaches its maximum 771 intensity within the CP domain. Note also that this larger domain is also enlarged 772 towards the east, to better capture the incoming flow from the northeastern and 773 from the Atlantic Ocean which increases the moisture flux towards SESA. The 774 one-step nesting simulations, for both the CP2 and CP3 domains, showed major 775

differences against the rest of the $\mathrm{CP}$ simulations in terms of the minimum skillful

spatial scales, suggesting that these simulations outperform in the representation of localized heavy rainfall all along the temporal evolution of the events. Additionally, these simulations reproduced the synoptic forcings associated with the events similarly compared with the two-nesting simulation over the $25^{\circ} \times 16^{\circ}$ domain. It was also noted that the spread among ensemble members turned out to be slightly smaller for the one-nesting approach compared with the two-nesting approach, as expected, particularly evident after the decay of the extreme event. This occurs also for the larger CP domain. This feature is particularly important when considering CP simulations covering longer periods.

Focusing specifically on the one-step nesting approach, it is found that enlarging the CP domain has some benefits and some drawbacks. The larger CP domain allows the synoptic drivers of the extreme events being better reproduced, given the importance of the topography in modulating the low-level circulation. On the other hand, the computational cost of the simulations also increases, and this may limit the technical capability for performing longer term climatic simulations. It is worth highlighting that the computational cost of the one-step nesting CP2-4 ensemble resulted $30 \%$ less expensive compared with the two-step nesting CP24(12). Additionally, the one-step nesting CP3-4 ensemble yielded a computational cost similar to that of two-step nesting CP2-4(12) ensemble, but with a considerably larger CP domain. Moreover, it is demonstrated that for the three individual events evaluated in this work, the one-step nesting CP simulations do not dete- 
riorate the quality of the simulated fields compared with the two-step nesting, independently of the size of the CP domain. This behavior may have important consequences for longer, climatic scale CP simulations. A major drawback in the one-step nesting approach is the resolution jump between the model providing the LBC and the CPM. Brisson et al (2015) suggested that the larger the resolution jump the larger the area close to the boundaries that should be discarded due to the spatial spin-up. Moreover, given that multiple nestings increases the biases that are transferred from one domain to another, the one-step nesting approach may prevent this major shortcoming.

Given the multiple evidence of the advantages and limitations of the various CP configurations discussed in this study, we consider the one-step nesting approach operating at $4 \mathrm{~km}$ over the D3 domain as the recommended CPM configuration for SESA. We are aware, however, that the simulations evaluated here last 72 hours and hence are strongly controlled by the initial conditions. Though the behavior of longer-term simulations covering various months or years cannot be directly extrapolated from this exercise, the results described in this work can be considered as a guidance for planning long-term climatic simulations over SESA with CPM ensembles.

Ban N, Schmidli J, Schär C (2015) Heavy precipitation in a changing climate: Does $\quad 817$ short-term summer precipitation increase faster? Geophysical Research Letters $\quad 818$ 42, DOI https://doi.org/10.1002/2014GL062588 819

Ban N, Rajczak J, Schmidli J, Schär C (2020) Analysis of alpine precipitation 820 extremes using generalized extreme value theory in convection-resolving climate 821 simulations. Climate Dynamics 55, DOI https://doi.org/10.1007/s00382-018- ${ }_{822}$ 4339-4

Ban N, Caillaud C, Coppola E, Pichelli E, Sobolowski S, Adinolfi M, Ahrens ${ }^{824}$ B, Alias A, Anders I, Bastin S, Belušić D, Berthou S, Brisson E, Cardoso 825 
R, Chan S, Christensen O, Fernández J, Fita L, Frisius T, Zander M (2021) 826

The first multi-model ensemble of regional climate simulations at kilometer- ${ }_{827}$ scale resolution, part i: evaluation of precipitation. Climate Dynamics DOI ${ }_{828}$ https://doi.org/10.1007/s00382-021-05708-w 829

Beck H, Vergopolan N, Pan M, Levizzani V, van Dijk A, Weedon G, Brocca L, Pap- 830 penberger F, Huffman G, Wood E (2017) Global-scale evaluation of 22 precipi- 831 tation datasets using gauge observations and hydrological modeling. Hydrology 832 and Earth System Sciences 21:6201-6217, DOI https://doi.org/10.5194/hess-216201-2017

Beck H, Wood E, Pan M, Fisher C, Miralles D, van Dijk A, McVicar T, Adler R (2018) MSWEP v2 global 3-hourly $0.1^{\circ}$ precipitation: Methodology and quantitative assessment. Bulletin of the American Meteorological Society 100, DOI https://doi.org/10.1175/BAMS-D-17-0138.1

Berthou S, Kendon E, Chan S, Ban N, Leutwyler D, Schär C, Fosser G (2020) Pan-european climate at convection-permitting scale: a model intercomparison study. Climate Dynamics 55, DOI https://doi.org/10.1007/s00382-018-4114-6

Bettolli M, Solman S, Rocha R, Llopart M, Gutierrez J, Fernández J, Olmo M, Lavín Gullón A, Chou S, Carneiro Rodrigues D, Coppola E, BalmacedaHuarte R, Barreiro M, Blazquez J, Doyle M, Feijoó M, Huth R, Machado L, Vianna Cuadra S (2021) The CORDEX Flagship Pilot Study in southeastern South America: a comparative study of statistical and dynamical downscaling models in simulating daily extreme precipitation events. Climate Dynamics 56:3, DOI https://doi.org/10.1007/s00382-020-05549-z

Blazquez J, Solman S (2020) Multiscale precipitation variability and extremes over South America: analysis of future changes from a set of CORDEX regional climate model simulations. Climate Dynamics 55, DOI https://doi.org/10.1007/s00382-020-05370-8

Brisson E, Demuzere M, Nicole V (2015) Modelling strategies for performing convective permitting climate simulations. Meteorologische Zeitschrift 25, DOI 
https://doi.org/10.1127/metz/2015/0598

Cerón W, Kayano M, Andreoli R, Avila-Diaz A, Ayes I, Freitas E, Martins J, Souza R (2020) Recent intensification of extreme precipitation events in the La Plata Basin in Southern South America (1981-2018). Atmospheric Research DOI https://doi.org/10.1016/j.atmosres.2020.105299

Chou SC, Lyra A, Mourão C, Dereczynski C, Pilotto I, Gomes J, Bustamante J,

Tavares P, Silva A, Rodrigues D, Campos D, Chagas D, Medeiros G, Siqueira

G, Marengo J (2014) Assessment of climate change over South America under 862

RCP 4.5 and 8.5 downscaling scenarios. American Journal of Climate Change 863

03:512-527, DOI https://doi.org/10.4236/ajcc.2014.35043 864

Coppola E, Sobolowski S, Pichelli E, Raffaele F, Ahrens B, Anders I, Ban N, ${ }_{865}$ Bastin S, Belda M, Belusic D, Caldas-Alvarez A, Cardoso R, Davolio S, Dobler $\quad 866$ A, Fernández J, Fita L, Fumiere Q, Giorgi F, Goergen K, Warrach-Sagi K (2020) 867 A first-of-its-kind multi-model convection permitting ensemble for investigating $\quad 868$ convective phenomena over Europe and the Mediterranean. Climate Dynamics 869 55, DOI https://doi.org/10.1007/s00382-018-4521-8 870

Cui W, Dong X, Xi B, Feng Z, Fan J (2019) Can the GPM IMERG Fi- 871 nal Product accurately represent MCSs' precipitation characteristics over the 872 central and eastern United States? Journal of Hydrometeorology 21, DOI 873 https://doi.org/10.1175/JHM-D-19-0123.1 874

Dee D, Uppala SM, Simmons AJ, Berrisford P, Poli P, Kobayashi S, Andrae U, ${ }_{875}$ Balmaseda M, Balsamo G, Bauer P, Bechtold P, Beljaars ACM, van de Berg L, 876 Bidlot J, Bormann N, Delsol C, Dragani R, Fuentes M, Geer AJ, Haimberger L, 877 Healy S, Hersbach H, Hólm EV, Isaksen L, Kallberg P, Kohler M, Matricardi M, 878 McNally AP, Monge-Sanz BM, Morchette J, Park BK, Peubey C, de Rosnay P, 879 Tavolato C, Thépaut JN, Vitart F (2011) The ERA-Interim reanalysis: Configu- $\quad 880$ ration and performance of the data assimilation system. Quarterly Journal of the $\quad 881$ Royal Meteorological Society 137:553-597, DOI https://doi.org/10.1002/qj.828 882 
Demaria E, Rodriguez D, Ebert E, Salio P, Su F, Valdes J (2011) Evaluation of ${ }_{883}$ mesoscale convective systems in South America using multiple satellite products $\quad 884$ and an object-based approach. Journal of Geophysical Research-Atmospheres 885 116, DOI https://doi.org/10.1029/2010jd015157 886

Dudhia J (1989) Numerical study of convection observed during the winter 887 monsoon experiment using a mesoscale two-dimensional model. Journal of 888 The Atmospheric Sciences 46:3077-3107, DOI https://doi.org/10.1175/1520- 889 0469(1989)046<3077:NSOCOD>2.0.CO;2

Falco M, Carril A, Menéndez C, Zaninelli P, Li L (2019) Assessment of CORDEX simulations over South America: added value on seasonal climatology and resolution considerations. Climate Dynamics 52, DOI https://doi.org/10.1007/s00382018-4412-z

Fantini A, Raffaele F, Torma C, Bacer S, Coppola E, Giorgi F, Ahrens B, Dubois C, Sanchez E, Verdecchia M (2018) Assessment of multiple daily precipitation statistics in ERA-Interim driven Med-CORDEX and EURO-CORDEX experiments against high resolution observations. Climate Dynamics 51, DOI https://doi.org/10.1007/s00382-016-3453-4

Fosser G, Khodayar Pardo S, Berg P (2014) Benefit of convection permitting climate model simulations in the representation of convective precipitation. Climate Dynamics 44:45-60, DOI https://doi.org/10.1007/s00382-014-2242-1

Fosser G, Khodayar S, Berg P (2016) Climate change in the next 30 years: What can a convection-permitting model tell us that we did not already know? Climate Dynamics DOI https://doi.org/10.1007/s00382-016-3186-4

Grell G, Freitas S (2014) A scale and aerosol aware stochastic convective parameterization for weather and air quality modeling. Atmospheric Chemistry and Physics Discussions 13, DOI 1https://doi.org/0.5194/acp-14-5233-2014

Hersbach H, Bell B, Berrisford P, Horányi A, Sabater JM, Nicolas J, Radu R, Schepers D, Simmons A, Soci C, Dee D (2019) Global reanalysis: goodbye ERA-Interim, hello ERA5. ECMWF Newsletter 156, DOI 
https://doi.org/10.21957/vf291hehd7

Hersbach H, Bell B, Berrisford P, Hirahara S, Horányi A, Muñoz Sabater J, Nicolas J, Peubey C, Radu R, Schepers D, Simmons A, Soci C, Abdalla S, Abellan X, Balsamo G, Bechtold P, Biavati G, Bidlot J, Bonavita M, Thépaut JN (2020) The ERA5 global reanalysis. Quarterly Journal of the Royal Meteorological Society DOI https://doi.org/10.1002/qj.3803

Hibino K, Takayabu I, Wakazuki Y, Ogata T (2018) Physical responses of convective heavy rainfall to future warming condition: Case 919 study of the Hiroshima event. Frontiers in Earth Science 6, DOI 920 https://doi.org/10.3389/feart.2018.00035 921

Hong SY, Jang J (2018) Impacts of shallow convection processes on a simulated ${ }_{922}$ boreal summer climatology in a global atmospheric model. Asia-Pacific Journal ${ }_{923}$ of Atmospheric Sciences 54:361-370, DOI https://doi.org/10.1007/s13143-018- 924 0013-3

Hong SY, Noh Y, Dudhia J (2006) A new vertical diffusion package with an ex- ${ }_{926}$ plicit treatment of entrainment processes. Monthly Weather Review 134, DOI 927 https://doi.org/10.1175/MWR3199.1 928

Huffman G, Bolvin D, Nelkin E, Adler R (2011) Highlights of Version 7 TRMM ${ }_{929}$ Multi-satellite Precipitation Analysis (TMPA). 5th Internat Precip Working 930 Group Workshop, Workshop Program and Proceedings pp 109-110 931

Huffman G, Stocker E, Bolvin D, Nelkin E, Jackson T (2019) GPM IMERG Final ${ }_{932}$ Precipitation L3 Half Hourly 0.1 degree x 0.1 degree V06, Greenbelt, MD, God- 933 dard Earth Sciences Data and Information Services Center (GES DISC). URL ${ }_{934}$ https://doi.org10.5067/GPM/IMERG/3B-HH/06 935

Janjic Z (1994) The step-mountain eta coordinate model: Further develop- 936 ment of the convection, viscous sublayer, and turbulent closure schemes. 937 Monthly Weather Review 122:927-945, DOI https://doi.org/10.1175/1520- 938 0493(1994)122<0927:TSMECM>2.0.CO;2 
Janjic Z (2002) Nonsingular implementation of the Mellor-Yamada Level $2.5 \quad 940$ scheme in the NCEP meso model. NCEP Office Note 436

Jimenez P, Dudhia J, González Rouco JF, Navarro J, Montávez J, Garcia Bus- 942 tamante E (2012) A revised scheme for the WRF surface layer formula- 943 tion. Monthly Weather Review 140, DOI https://doi.org/10.1175/MWR-D-11- 944 00056.1

Joyce R, Janowiak J, Arkin P, Xie P (2004) CMORPH: A method that pro- ${ }_{946}$ duces global precipitation estimates from passive microwave and infrared data ${ }_{947}$ at high spatial and temporal resolution. Journal of Hydrometeorology 5, DOI https://doi.org/10.1175/1525-7541(2004)005<0487:CAMTPG>2.0.CO;2

Kain J (2004) The Kain-Fritsch convective parameterization: An update. Journal of Applied Meteorology 43:170-181, DOI https://doi.org/10.1175/15200450(2004)04360;0170:tkcpau62;2.0.co;2

Kendon E, Roberts NM, Senior CA, Roberts MJ (2012) Realism of rainfall in a very high-resolution regional climate model. Journal of Climate 25(17):57915806, DOI https://doi.org/10.1175/JCLI-D-11-00562.1

Kendon E, Roberts N, Fowler H, Roberts M, Chan S, Senior C (2014) Heavier summer downpours with climate change revealed by weather forecast resolution model. Nature Climate Change 4:570-576, DOI https://doi.org/10.1038/nclimate2258

Kendon E, Ban N, Roberts N, Fowler H, Roberts M, Chan S, Evans J, Fosser G, Wilkinson J (2016) Do convection-permitting regional climate models improve projections of future precipitation change? Bulletin of the American Meteorological Society 98, DOI https://doi.org/10.1175/BAMS-D-15-0004.1

Lavín Gullón A, Feijoó M, Solman S, Fernández J, Rocha R, Bettolli M (2021) Synoptic forcing associated with extreme precipitation events over Southeastern South America as depicted by a CORDEX FPS set of convection-permitting RCMs. Climate Dynamics 56, DOI https://doi.org/10.1007/s00382-021-05637-8 
Li J, Chen H, Rong X, Su J, Xin Y, Furtado K, Milton S, Li N (2018) How well can a climate model simulate an extreme precipitation event: A case study using the Transpose-AMIP experiment. Journal of Climate 31, DOI https://doi.org/10.1175/JCLI-D-17-0801.1

Li P, Guo Z, Furtado K, Chen H, Li J, Milton S, Field P, Zhou T (2019) Prediction of heavy precipitation in the eastern China flooding events of 2016: Added value of convection-permitting simulations. Quarterly Journal of the Royal Meteorological Society 145, DOI https://doi.org/10.1002/qj.3621

Lim KS, Hong SY (2010) Development of an effective Double-Moment Cloud Microphysics scheme with prognostic cloud condensation nuclei (CCN) for 977 weather and climate models. Monthly Weather Review 138:1587-1612, DOI 978 https://doi.org/10.1175/2009MWR2968.1 979

Liu C, Ikeda K, Rasmussen R, Barlage M, Newman A, Prein A, Chen L, Clark 980 M, Dai A, Dudhia J, Eidhammer T, Gochis D, Gutmann E, Kurkute S, Li Y, ${ }_{981}$ Thompson G, Yates D (2017) Continental-scale convection-permitting modeling 982 of the current and future climate of North America. Climate Dynamics 49, DOI 983 https://doi.org/10.1007/s00382-016-3327-9 984

Mahoney K, Thompson G, Barsugli JJ, Scott JD, Alexander M (2012) Changes 985 in hail and flood risk in high-resolution simulations over Colorado's mountains. 986 Nature Climate Change 2, DOI https://doi.org/10.1038/nclimate1344 987 Matsudo C, Salio P (2011) Severe weather reports and proximity to deep con- ${ }_{988}$ vection over Northern Argentina. Atmospheric Research 100:523-537, DOI ${ }_{989}$ https://doi.org/10.1016/j.atmosres.2010.11.004 990 Matsudo C, García Skabar Y, Ruiz J, Vidal L, Salio P (2015) Verification of WRF- 991 ARW convective-resolving forecasts over Southeastern South America. Mausam 992 $66: 445-456 \quad 993$

Matsui T, Zhang S, Lang S, Tao WK, Ichoku C, Peters-Lidard C (2020) Impact 994 of radiation frequency, precipitation radiative forcing, and radiation column ag- $\quad 995$ gregation on convection-permitting West African monsoon simulations. Climate 996 
Dynamics 55, DOI https://doi.org/10.1007/s00382-018-4187-2 997

Matte D, Lucas-Picher P (2017) Spatial spin-up of fine scales in a regional cli- 998 mate model simulation driven by low-resolution boundary conditions. Climate 999 Dynamics 49:1-12, DOI https://doi.org/10.1007/s00382-016-3358-2 1000

Mlawer E, Taubman S, Brown P, Iacono M, Clough S (1997) Radiative trans- ${ }_{1001}$ fer for inhomogeneous atmospheres: RRTM, a validated correlated-k model ${ }_{1002}$ for the longwave. Journal of Geophysical Research 102:16663-16682, DOI ${ }_{1003}$ https://doi.org/10.1029/97JD00237 1004

Nakanishi M, Niino H (2009) Development of an improved turbulence closure 1005 model for the atmospheric boundary layer. Journal of the Meteorological Society of Japan 87:895-912, DOI https://doi.org/10.2151/jmsj.87.895

Olmo M, Bettolli M (2021) Extreme daily precipitation in southern South America: statistical characterization and circulation types using observational datasets and regional climate models. Climate Dynamics DOI https://doi.org/10.1007/s00382-021-05748-2

Olmo M, Bettolli M, Rusticucci M (2020) Atmospheric circulation influence on temperature and precipitation individual and compound daily extreme events: Spatial variability and trends over southern South America. Weather and Climate Extremes 29:100267, DOI https://doi.org/10.1016/j.wace.2020.100267

Pall P, Patricola C, Wehner M, Stone D, Paciorek C, Collins W (2017) Diagnosing conditional anthropogenic contributions to heavy Colorado rainfall in September 2013. Weather and Climate Extremes 17, DOI https://doi.org/10.1016/j.wace.2017.03.004

Penalba O, Robledo F (2010) Spatial and temporal variability of the frequency of extreme daily rainfall regime in the La Plata Basin during the 20th century. Climatic Change 98:531-550, DOI https://doi.org/10.1007/s10584-009-9744-6

Pichelli E, Coppola E, Sobolowski S, Ban N, Giorgi F, Stocchi P, Alias A, Belušić D, Berthou S, Caillaud C, Cardoso R, Chan S, Christensen O, Dobler A, de Vries H, Goergen K, Kendon E, Keuler K, Lenderink G, Vergara-Temprado J (2021) 
The first multi-model ensemble of regional climate simulations at kilometer-scale resolution part 2: historical and future simulations of precipitation. Climate Dynamics 56, DOI https://doi.org/10.1007/s00382-021-05657-4

Prein A, Gobiet A, Suklitsch M, Truhetz H, Awan N, Keuler K, Georgievski G (2013) Added value of convection permitting seasonal simulations. Climate Dynamics 41, DOI https://doi.org/10.1007/s00382-013-1744-6

Prein A, Langhans W, Fosser G, Ferrone A, Ban N, Goergen K, Keller M, Tölle M, Gutjahr O, Feser F, Brisson E, Kollet S, Schmidli J, P M van Lipzig N, Leung L (2015) A review on regional convection-permitting climate modeling: Demonstrations, prospects, and challenges. Reviews of Geophysics 53, DOI 1035 https://doi.org/10.1002/2014RG000475 1036

Prein A, Liu C, Ikeda K, Bullock R, Rasmussen R, Holland G, Clark ${ }_{1037}$ M (2020a) Simulating North American mesoscale convective systems with 1038 a convection-permitting climate model. Climate Dynamics 55, DOI 1039 https://doi.org/10.1007/s00382-017-3993-2 1040

Prein A, Rasmussen R, Castro C, Dai A, Minder J (2020b) Special issue: Ad- ${ }_{1041}$ vances in convection-permitting climate modeling. Climate Dynamics 55, DOI 1042 https://doi.org/10.1007/s00382-020-05240-3 ${ }^{1043}$

Rasmussen K, Houze R (2016) Convective initiation near the Andes ${ }_{1044}$ in subtropical South America. Monthly Weather Review 144, DOI ${ }_{1045}$ https://doi.org/10.1175/MWR-D-15-0058.1 1046

Rasmussen K, Chaplin MM, Zuluaga MD, Houze RA (2016) Contribution of ex- ${ }_{1047}$ treme convective storms to rainfall in South America. Journal of Hydrometeo- ${ }_{1048}$ rology 17(1):353-367, DOI https://doi.org/10.1175/JHM-D-15-0067.1 1049

Rasmussen K, Prein A, Rasmussen R, Ikeda K, Liu C (2020) Changes in the con- 1050 vective population and thermodynamic environments in convection-permitting 1051 regional climate simulations over the United States. Climate Dynamics 55, DOI 1052 https://doi.org/10.1007/s00382-017-4000-7 1053 
Roberts NM, Lean HW (2008) Scale-selective verification of rainfall accumulations ${ }^{1054}$ from high-resolution forecasts of convective events. Monthly Weather Review 1055 136(1):78-97, DOI https://doi.org/10.1175/2007MWR2123.1 1056

Romatschke U, Houze R (2013) Characteristics of precipitating convective systems $\quad 1057$ accounting for the summer rainfall of tropical and subtropical South America. ${ }^{1058}$ Journal of Hydrometeorology 14:25-46, DOI https://doi.org/10.1175/JHM-D- ${ }_{1059}$ $12-060.1$

Salio P, Nicolini M, Zipser E (2007) Mesoscale convective systems over southeast- 1061 ern south america and their relationship with the South American Low-Level 1062

Jet. Monthly Weather Review 135, DOI https://doi.org/10.1175/MWR3305.1

Salio P, Hobouchian M, García Skabar Y, Vila D (2014) Evaluation of high-resolution satellite precipitation estimates over southern South America using a dense rain gauge network. Atmospheric Research 163, DOI https://doi.org/10.1016/j.atmosres.2014.11.017

Skamarock W, Klemp J, Dudhia J, O Gill D, Barker D, Wang W, G Powers J (2008) A description of the Advanced Research WRF Version 3. NCAR Technical Note NCAR/TN-468+STR, DOI https://doi.org/10.5065/D68S4MVH

Solman S (2016) Systematic temperature and precipitation biases in the CLARIS-LPB ensemble simulations over South America and possible implications for climate change projections. Climate Research 68, DOI https://doi.org/10.3354/cr01362

Solman S, Blazquez J (2019) Multiscale precipitation variability over South America: Analysis of the added value of CORDEX RCM simulations. Climate Dynamics DOI https://doi.org/10.1007/s00382-019-04689-1

Solman S, Sanchez E, Samuelsson P, da Rocha RP, Li L, Marengo J, Pessacg N, Remedio AR, Chou SC, Berbery H, Le Treut H, de Castro M, Jacob D (2013) Evaluation of an ensemble of regional climate model simulations over South America driven by the ERA-Interim reanalysis: Model performance and uncertainties. Climate Dynamics 41, DOI https://doi.org/10.1007/s00382-013- 
$1667-2$

Solman S, Bettolli M, Doyle M, Olmo M, Feijoó M, Martinez D, Blazquez J, Balmaceda-Huarte R (2021) Evaluation of multiple downscaling tools for simulating extreme precipitation events over Southeastern 1086 South America: a case study approach. Climate Dynamics pp 1-24, DOI ${ }_{1087}$ https://doi.org/10.1007/s00382-021-05770-4

Tewari M, Wang W, Dudhia J, LeMone M, Mitchell K, Ek M, Gayno G, Wegiel ${ }_{1089}$ J, Cuenca R (2016) Implementation and verification of the united NOAH land ${ }_{1090}$ surface model in the wrf model. pp 11-15 1091

Torma C, Giorgi F, Coppola E (2015) Added value of regional climate mod- ${ }_{1092}$ eling over areas characterized by complex terrain-precipitation over the 1093 Alps. Journal of Geophysical Research: Atmospheres 120(9):3957-3972, DOI 1094 https://doi.org/10.1002/2014JD022781 1095

Vörösmarty C, Bravo de Guenni L, Wollheim W, Pellerin B, Bjerklie D, Cardoso 1096 M, D'Almeida C, Green P, Colon L (2013) Extreme rainfall, vulnerability and ${ }_{1097}$ risk: A continental-scale assessment for South America. Philosophical transac- ${ }_{1098}$ tions Series A, Mathematical, physical, and engineering sciences 371:20120408, 1099 DOI https://doi.org/10.1098/rsta.2012.0408 ${ }_{1100}$

Yang Q, Houze R, Leung L, Feng Z (2017) Environments of long-lived mesoscale ${ }_{1101}$ convective systems over the central United States in convection permitting cli- ${ }_{1102}$ mate simulations. Journal of Geophysical Research: Atmospheres 122, DOI ${ }_{1103}$ https://doi.org/10.1002/2017jd027033 1104

Yun Y, Liu C, Luo Y, Liang X, Huang L, Chen F, Rasmmusen R (2020) ${ }_{1105}$ Convection-permitting regional climate simulation of warm-season precipitation ${ }_{1106}$ over eastern China. Climate Dynamics 54, DOI https://doi.org/10.1007/s00382- ${ }_{1107}$ 019-05070-y

Zipser E, J Cecil D, Liu C, Nesbitt S, Yorty D (2006) Where are the most intense ${ }_{1109}$ thunderstorms on Earth? Bulletin of The American Meteorological Society 87, 1110 DOI https://doi.org/10.1175/BAMS-87-8-1057 